ISSN: 0213-2079 - ISSN electrónico: 2386-3889

DOI: https://doi.org/10.14201/shhmo20204225789

\title{
MERCADERES EN LAS URBES: LOS SOPRANIS, GENOVESES GADITANOS EN ESPAÑA Y EN AMÉRICA ${ }^{1}$
}

\section{Merchants in the Cities: The Sopranis, Genoese from Cádiz in Spain and America}

\section{Juan José IGLESIAS RODRÍGUEZ}

Departamento de Historia Moderna de la Universidad de Sevilla jjiglesias@us.es

Fecha de recepción: 11/09/2020

Fecha de aceptación: 20/10/2020

RESUMEN: Este artículo trata de profundizar en la realidad de los comerciantes de la Carrera de Indias como agentes mercantiles, pero, sobre todo, como protagonistas de la cultura urbana y como conectores culturales en un mundo crecientemente integrado. Con este fin, aborda el estudio de los Sopranis, una familia de mercaderes de origen genovés que tuvo una activa presencia en Andalucía y en Canarias. El trabajo se centra específicamente en la rama familiar de los Sopranis instalada en Cádiz, ciudad que ejerció un decisivo papel en las relaciones de España con el norte de África, el archipiélago canario y los nuevos espacios coloniales americanos. En Cádiz, los Sopranis desempeñaron una intensa actividad como cargadores y navieros, al tiempo que se insertaron eficazmente en la oligarquía local de regidores perpetuos y jugaron un papel decisivo en la conformación de las

1. Este trabajo se enmarca en el Proyecto de $\mathrm{I}+\mathrm{D}+\mathrm{i}$ «La construcción de un mundo nuevo: circuitos económicos, dinámicas sociales y mediadores culturales en las ciudades atlánticas del sur de España, siglos XVI-XVIII» (HAR2017-85305-P), así como en el Proyecto I+D+i FEDER Andalucía «En torno a la Primera Globalización: circulaciones y conexiones entre el Atlántico y el Mediterráneo (1492-1824)» (US-1262566). 
redes relacionales y el desarrollo de las manifestaciones culturales propias de la élite urbana dominante.

Palabras clave: Comerciantes genoveses; oligarquías urbanas; Carrera de Indias; cultura urbana; siglos XVI y XVII.

ABSTRACT: The aim of this paper is to delve into the merchants who were involved in the Carrera de Indias not merely as commercial agents, but mostly as protagonists of urban culture and cultural connectors in an increasingly integrated world. To this end, it addresses the study of the Sopranis, a Genoese merchant family whose members actively worked in Andalusia and the Canary Islands. The present paper focuses specifically on the Sopranis branch based in Cadiz, a city that played a major role in Spain's relations with North Africa, the Canary Islands and the new colonial areas in the West Indies. In Cadiz they carried out an intense activity as merchants and shipowners, while effectively inserting themselves into the local oligarchy of regidores perpetuos and played a decisive role in the formation of relational networks and the development of the dominant elite's urban cultural manifestations.

Keywords: Genoese merchants; urban oligarchies; Carrera de Indias; urban culture; 16th and 17th centuries.

\section{INTRODUCCIÓN}

La Edad Moderna fue el escenario de la construcción de un mundo nuevo que integró áreas geográficamente muy lejanas entre sí, pero interconectadas de forma creciente a través de una densa red de intercambios. Los mercaderes jugaron un papel fundamental en la organización de este sistema progresivamente integrado y en el trenzado de esa urdimbre de relaciones, en la que se ha visto con buenas razones la puesta en marcha de una primera globalización (Hopkins, 2002; Gruzinski, 2010). Los comerciantes fueron, antes que nada, los agentes económicos que se encargaron de gestar aquel primer sistema mundial. Pero también fueron conectores culturales, portadores no sólo de saberes mercantiles, sino también de ideas, creencias y artefactos culturales diversos que contribuyeron a la conformación de un imaginario y de una realidad nueva con un gran potencial expansivo. A través de sus viajes y de sus 
JUAN JOSÉ IGLESIAS RODRÍGUEZ

MERCADERES EN LAS URBES: LOS SOPRANIS, GENOVESES GADITANOS

EN ESPAÑA Y EN AMÉRICA

complejas relaciones mercantiles operaron, por una parte, como agentes globales ${ }^{2}$; pero, al mismo tiempo, al insertarse activamente en la sociedad de las urbes en las que radicaron, actuaron también como agentes locales con una considerable capacidad para transformar profundamente el universo mental que habían heredado. En esta doble dimensión local y global, más acusada aún si cabe en las ciudades portuarias abiertas al mar, es donde alcanzamos a valorar más acertadamente la dimensión del papel histórico que desempeñaron.

El comercio del bajo medievo y de comienzos de la Edad Moderna dio origen a la existencia de unas comunidades mercantiles muy internacionalizadas en los principales centros urbanos que protagonizaron su desarrollo. Entre sus más destacados agentes estuvieron los mercaderes italianos, especialmente los genoveses, que ampliaron su radio de acción del Mediterráneo al Atlántico a partir de los siglos XIII y XIV. Los genoveses establecieron sólidas colonias mercantiles en las ciudades y puertos del Atlántico andaluz (Pike, 1966; Boscolo, 1974; Heers, 1982; Pistarino, 1985; D’Arienzo, 1986; Ladero, 1989; Bello, 1993; González Arce, 2010; Perez, 2016a), que operaron en principio como escalas en las rutas que vincularon comercialmente a las ciudades del norte de Italia con la Europa septentrional, y que más tarde desempeñaron un papel muy activo en la expansión atlántica de la corona castellana.

Junto a Sevilla, Cádiz constituye un observatorio excepcional para el propósito de este trabajo. La privilegiada posición de esta ciudad la convirtió en un entrepôt clave en las rutas que unieron el Mediterráneo y el Atlántico. El comercio con el norte de África, del que Cádiz llegó a ostentar el monopolio (Rumeu de Armas, 1956-1957; 1976), y las relaciones con las islas Canarias impulsaron también el papel portuario y mercantil de Cádiz. Finalmente, el descubrimiento, conquista y colonización de América propició la organización de un sistema de comercio y navegación en el que Sevilla asumió el protagonismo principal, pero en el que Cádiz tuvo también una importancia extraordinaria.

Todos ellos fueron factores para que, entre los siglos XIV y XVI, la presencia genovesa fuese tan intensa como determinante (Pellegrini, 2003-2004; Ríos, 2018). Desde la primera de aquellas centurias se constata ya el asentamiento de una familia de comerciantes genoveses firmemente arraigada en la ciudad, los Marrufo, que actuaron como cónsules de la nación genovesa en Cádiz y accedieron al gobierno urbano de la ciudad. En el siglo XV, la colonia genovesa incrementó su importancia y efectivos (Sánchez Herrero, 1981; Sánchez Saus, 2005). El padrón de 1467 revela la presencia de numerosos genoveses en Cádiz, entre ellos los Bonifacio, Cataño, Doria, Escanio, Espínola, Manroba, Machorro, Sestón o los propios Marrufo

2. La historiografía especializada está prestando en tal sentido una gran importancia al estudio de las redes mercantiles (Crespo, 2015; Herrero y Kaps, 2017). 
JUAN JOSÉ IGLESIAS RODRÍGUEZ

MERCADERES EN LAS URBES: LOS SOPRANIS, GENOVESES GADITANOS EN ESPAÑA Y EN AMÉRICA

(Martín, 2006). Este número siguió aumentando a buen ritmo en los últimos años del siglo XV y los primeros del siglo XVI, hecho en el que debieron influir sin duda las expectativas generadas por la definitiva conquista del archipiélago canario y por la apertura del mercado colonial americano. En el empréstito para el asedio de Baza de 1489 se repartieron 323.000 maravedís a veintidós mercaderes estantes en Cádiz y dos residentes en El Puerto de Santa María (D’Arienzo, 1993). Enrique Otte ofrece, por su parte, un listado de 106 mercaderes genoveses presentes en Cádiz entre 1496 y 1515, a los que se suman otros doce en El Puerto de Santa María, nueve en Jerez de la Frontera y seis en Sanlúcar de Barrameda (Otte, 1996). Así pues, las redes genovesas presentaban en Cádiz una gran densidad, al punto que alguna fuente coetánea les atribuye, probablemente de forma excesiva, un mayor peso demográfico que a los propios españoles en la sociedad urbana gaditana (Igual y Navarro, 1997: 273-274). Como queda dicho, Cádiz no hizo sino reforzar su importancia mercantil en los siglos XVI y XVII, preludio del momento estelar de la ciudad, la decimoctava centuria. Agustín de Horozco, que escribió una historia de la ciudad a fines del siglo XVI, atribuyó la prosperidad de Cádiz a las excelentes condiciones que ofrecían su puerto y su bahía para el desarrollo del trato mercantil (Horozco, 1845). Y, algún tiempo después, fray Jerónimo de la Concepción calificaría a Cádiz como un auténtico «emporio del Orbe»(Concepción, 1690).

\section{LOS SOPRANIS EN ESPAÑA}

Entre los mercaderes genoveses activos en España a comienzos de la Edad Moderna encontramos a numerosos Sopranis. En Sevilla, un Bernardo Sopranis aparece en la relación de los comerciantes de aquella nación que contribuyeron al préstamo para el asedio de Baza en 1489. Enrique Otte documenta también su activo papel en el comercio del aceite andaluz. Así, por ejemplo, Jacopo Sopranis compró en 1515 al regidor sevillano Francisco de Alcázar cuarenta mil quintales de aceite, por un valor de 3.750 .000 maravedís (Otte, 1996: 40). También desempeñaron un papel importante en el comercio del azúcar, del que los genoveses ejercieron un cuasi monopolio. Desde 1480 aparece registrado en los protocolos notariales sevillanos el azúcar del Atlántico portugués como objeto de negocio. A partir de 1495, se incorporó también el azúcar canario, cuya importación se organizó desde Sevilla y, sobre todo, desde Cádiz, de donde se reexportaba hacia Amberes, Londres y diversos puertos mediterráneos, especialmente italianos, como Génova, Talamone, Cività Vecchia, Nápoles, Salerno o Venecia (Otte, 1996: 155-156). Por último, los Sopranis sevillanos aparecen también vinculados al comercio de manufacturas de cuero y tejidos de seda. De un total de 437 mercaderes genoveses que Otte documenta en Sevilla entre 1489 y 1514, catorce llevaban el apellido Sopranis. Algunos de ellos, como Jacopo y Antonio Sopranis, fueron elegidos cónsules de la nación genovesa presente en la ciudad (Otte, 1996: 186-187). 
JUAN JOSÉ IGLESIAS RODRÍGUEZ

MERCADERES EN LAS URBES: LOS SOPRANIS, GENOVESES GADITANOS EN ESPAÑA Y EN AMÉRICA

La presencia de los Sopranis en Canarias es para Hipólito Sancho muy temprana. Este historiador la eleva a los momentos inmediatamente subsiguientes a la conquista de las islas, en la década de los noventa del siglo XV (Sancho, 1951), aunque por los datos de otros autores la cuestión no es tan clara (Marrero, 1950). Pero, si bien la presencia del apellido Sopranis en Canarias en los primeros momentos de la conquista puede ofrecer dudas, no es así en el caso de los Riberol (los Rippariolo genoveses), vinculados familiarmente a aquellos. La apertura del mercado del azúcar canario atrajo a los hermanos Francisco y Cosme Riberol a Canarias (De la Rosa, 1972). Béatrice Perez ha estudiado el papel como propietario de ingenios azucareros en Canarias y en el mercado de azúcar y esclavos de Francisco de Riberol, un personaje imbricado en un sistema europeo de relaciones que gira en gran medida en torno a un complejo genovés que esta autora describe como «un sistema asociativo de redes a partir de una geografía salpicada (...), como una galaxia de constelaciones moviéndose alrededor de un eje poderoso» (Perez, 2016). Los Riberol participaron también intensamente en la producción y comercialización del jabón blanco sevillano, como arrendatarios de una importante almona en Triana (Otte, 1996: 65-72; Perez, 2016b).

Los Sopranis aparecen también a fines del siglo XV y comienzos del XVI en otras ciudades españolas. David Igual y Germán Navarro documentan la presencia de varios de ellos en Valencia, como Francesco di Sopranis, mercator ianuensis, Girolamo di Sopranis Donato, Giacomo di Sopranis o Cosimo di Sopranis, entre 1471 y 1515. Asimismo, Giacomo di Sopranis aparece en Jerez de la Frontera en 1482 (Igual y Navarro, 1997: 301).

Es preciso señalar que Sopranis era el gentilicio común que adoptaron los miembros de las diversas familias genovesas integradas en el albergo genovés del mismo nombre, que recibía esta denominación por el hecho de estar radicado en la contrada de la Porta Soprana. Los alberghi constituyeron una de las instituciones más características de Génova. Desde finales del siglo XIII se organizaron en ella los alberghi nobiliarios. Entre mediados del siglo XIV y comienzos del XVI se fueron formando los distintos alberghi popolari, integrados mayoritariamente por comerciantes, entre los cuales el de los Sopranis. La nueva constitución genovesa de 1528 consagró la existencia de los alberghi politici, reduciendo su número a veintiocho y obligando de este modo a un proceso de integración (De la Rosa, 1972).

A mediados del siglo XVI, varios individuos pertenecientes a una de aquellas familias genovesas integradas en el albergo de los Sopranis, los Cibo, se instalaron en España. Según Hipólito Sancho, formaron parte de una amplia emigración genovesa dirigida hacia la Península Ibérica que respondió a motivos políticos y económicos: la victoria definitiva de los Doria sobre la antigua nobleza y la crisis derivada de la pérdida a manos de los turcos de las posesiones que la república ligur mantenía en el Mediterráneo oriental. Para el mismo autor, fueron tres los Cibo de 
JUAN JOSÉ IGLESIAS RODRÍGUEZ

MERCADERES EN LAS URBES: LOS SOPRANIS, GENOVESES GADITANOS

EN ESPAÑA Y EN AMÉRICA

Sopranis que formaron parte de aquella diáspora: Rafael, que se asentó en Sevilla; Felipe, que lo hizo en Canarias, y Esteban, que se instaló en Cádiz. Todos eran hijos de Jácome Cibo de Sopranis y de Margarita Scaglia. A su vez, aquel descendía del patricio genovés Rafael Cibo de Sopranis y de su esposa, Marietta An’Doria (Sancho, 1951: 323-324).

El momento exacto en el que Esteban Cibo de Sopranis llegó a Cádiz no resulta fácil de determinar, toda vez que gran parte de la documentación de los archivos gaditanos desapareció en el incendio que padeció la ciudad durante el asalto angloholandés de 1596. Sin embargo, el propio Hipólito Sancho documenta su presencia activa en la ciudad en las décadas de 1550 y 1560, a través de diversos protocolos notariales salvados de la destrucción. El más antiguo, al parecer, data de 1553. Se trata de una escritura de venta de casas entre Reines Cob Velgres y Menat Pen, ambos flamencos, en la que consta que el inmueble estaba cargado con tres mil maravedís de tributo perpetuo a favor de Esteban Cibo de Sopranis y Luisa Gentil, su mujer, esta última también perteneciente por vía paterna a una familia de comerciantes de origen genovés, pues era hija de Esteban Gentile y de Catalina de Estopiñán. Para Luisa Gentil se trataba de su segundo matrimonio, ya que en primeras nupcias había estado casada con Antoniotto de Negrón, del que enviudó (Sancho, 1951: 330-335). Ambos cónyuges habían fallecido ya en 1578. Hay que decir que el apellido Sopranis aparece escrito de diferentes maneras. En la documentación que hemos manejado la más frecuente es Soberanis, pero también aparece como Soveranis, Sobranis, y Sovranis. La forma Sopranis se consolidó a partir del siglo XVIII.

Del matrimonio entre Esteban Cibo de Sopranis y Luisa Gentil nacieron seis hijos. El mayor, Jácome, casó con Juana Baricio de Haya, hija de Simón de Baricio y Teresa de Oribes. La segunda, Margarita de Sopranis, casó con Cristóbal Marrufo, asimismo, como ya se ha dicho, descendiente de una antigua familia de mercaderes genoveses asentada en Cádiz desde los tiempos bajomedievales. A estos siguieron Esteban Gentil de Sopranis; Agustín de Sopranis, casado con Juana Morteo; Rafael de Sopranis y Felipe de Sopranis.

Jácome Sopranis y Juana Baricio tuvieron, por su parte, una muy numerosa descendencia: un total de once hijos, de los cuales el mayor fue Esteban Sopranis, casado con Isabel Aguíniga de Negrón, aunque la continuidad del linaje vino de la mano del segundogénito, Simón, quien contrajo matrimonio con Clara Boquín de Bocanegra (ver cuadro genealógico adjunto). 
JUAN JOSÉ IGLESIAS RODRÍGUEZ

MERCADERES EN LAS URBES: LOS SOPRANIS, GENOVESES GADITANOS EN ESPAÑA Y EN AMÉRICA

Cuadro genealógico de los Sopranis

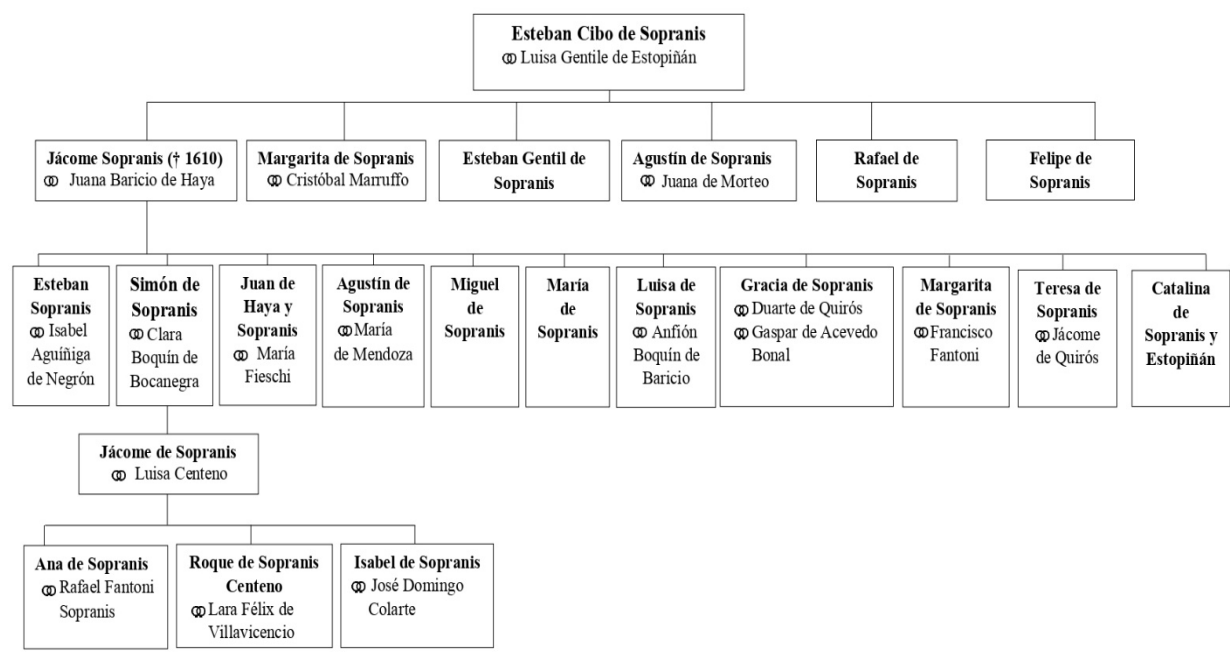

\section{LOS SOPRANIS EN AMÉRICA Y EN LA CARRERA DE INDIAS}

La vinculación de los Sopranis con América fue temprana. En 1535, Luis de Sopranis, hijo de Antonio de Sopranis y de Bernardina de Mendoza, pasó a Nueva España en una nao propiedad de Francisco de la Roca ${ }^{3}$. En la década siguiente, Bartolomé de Sopranis Ribera figuró entre los primeros pobladores de la ciudad de Mérida, en Yucatán, sirviendo como escribano a los gobernadores y alcaldes mayores de aquella provincia. Tras varias décadas al servicio del rey, en 1572 solicitaba ayudas de costa y trescientos pesos al año para mantener a su familia, ya que padecía necesidad por ser viejo y no tener indios repartidos ${ }^{4}$. El gaditano Agustín de Sopranis se ocupó en la Carrera de Indias, empleándose, entre otras cosas, en la importación de colorantes procedentes de América. En 1578 figura en un pleito sobre comiso de grana ${ }^{5}$. Unos años después, en 1584, el fiscal de la Casa de la Contratación procedió contra él, en este caso en el decomiso de un cajón de cochinilla ${ }^{6}$. En 1586 era dueño de una nao, la «Severa María Juncal» ${ }^{7}$, cuya propiedad compartía, al parecer, con su

3. Archivo General de Indias [AGI], Contratación, 5536, L. 3, F. 124 (4).

4. AGI, México, 211, N. 47.

5. AGI, Escribanía, 953.

6. AGI, Escribanía, 1069 B.

7. AGI, Contratación, 727, N. 1. Autos de Álvaro Mendoza de Carrizosa, vecinos de Jerez de la Frontera, contra Agustín de Soberanis, dueño de la nao «La Severa María del Juncal», sobre cobranza de 84 ducados de avería. 
JUAN JOSÉ IGLESIAS RODRÍGUEZ

MERCADERES EN LAS URBES: LOS SOPRANIS, GENOVESES GADITANOS

EN ESPAÑA Y EN AMÉRICA

hermano Esteban Gentil de Sopranis y que llegó a servir como almiranta de la Flota ${ }^{8}$. En 1587, este último pleiteó con Juan de Lambarri, maestre de raciones, sobre la cuenta de la nao ${ }^{9}$. Un tercer hermano, Felipe, hijo de Esteban Cibo de Sopranis y de Luisa Gentil de Estopiñán, pasó también a Nueva España. En 1581 solicitó a la Audiencia de México que le tomara información a fin de solicitar al rey un oficio de regidor u otro cargo de administración o justicia en aquella ciudad, o en cualquier otro lugar del virreinato ${ }^{10}$.

También fue dueño de una nao el capitán Duarte de Quirós, primer marido de Gracia de Sopranis. De su administración se ocupaba el tío de esta, Esteban Gentil de Sopranis, con quien Quirós pleiteó en 1603 en la Casa de la Contratación sobre sus cuentas, fletes y aprovechamientos ${ }^{11}$. Tres años más tarde, ya fallecido su esposo, Gracia de Sopranis tuvo que hacer frente a reclamaciones judiciales sobre sus bienes ${ }^{12}$. Por el testamento de Jácome de Sopranis, sabemos también que su hijo Simón pasó al Perú y luego fue a Nueva España, donde se hallaba en 1610, seguramente ocupándose de negocios mercantiles. En 1619, cuando se repartieron los bienes de su padre, estaba ya de vuelta en Cádiz.

En los años cuarenta del siglo XVII encontramos a otro Sopranis, Juan Francisco, como maestre de un patache de 140 toneladas, el «Nuestra Señora de la Concepción», de fábrica portuguesa, con el que realizó varios viajes en la Carrera de Indias. Así, en 1640 partió de Cádiz para Cumaná con la flota de Luis Fernández de Córdoba ${ }^{13}$. En 1643 salió del río Guadalquivir con la flota de Pablo Fernández de Contreras, en este caso con destino a La Habana ${ }^{14}$. Otro Sopranis propietario de un navío en la Carrera de Indias fue Pedro Sopranis de la Guerra, quien frecuentó las costas de Venezuela. En 1648 trajo una carga de tabaco fuera de registro en una fragata que venía de Maracaibo y que naufragó cerca de Gibraltar, siendo aprehendida la carga ${ }^{15}$. Murió en La Guaira una década después, en 1658, a bordo del navío «Virgen de los Reyes», del que era propietario, y que se aprestaba a hacerse a la vela rumbo a

8. AGI, Indiferente, 1952, L. 3, f. 94v-95. Real Cédula a los oficiales de la Casa de la Contratación para que de averías de armadas paguen a Agustín y Esteban de Soberanis el sueldo que les corresponde del tiempo que su nao sirvió de almiranta de la flota.

9. AGI, Contratación, 728, N. 3.

10. AGI, México, 216, N. 25.

11. AGI, Contratación, 754, N. 11.

12. AGI, Contratación, 766, N. 3. Autos de Garci Núñez contra los bienes del capitán Duarte de Quirós, difunto, vecinos y regidor de Cádiz, dueño de nao, y Gracia de Soberanis, su viuda, y herederos, sobre cobranza de maravedís.

13. AGI, Contratación, 1184, N. 2, R. 18. Registro de ida del patache «Nuestra Señora de la Concepción» para Cumaná.

14. AGI, Contratación, 1187, N. 4.

15. AGI, Contratación, 182, N. 7. 
JUAN JOSÉ IGLESIAS RODRÍGUEZ

MERCADERES EN LAS URBES: LOS SOPRANIS, GENOVESES GADITANOS

EN ESPAÑA Y EN AMÉRICA

Maracaibo $^{16}$. Seguidamente, nos referiremos a Simón Díez de Alda Sopranis, hijo de Miguel Díez de Alda y de Isabel Sopranis, quien embarcó en 1681 con destino a Tierra Firme en la flota comandada por el marqués de Brenes, en la que cargó diversas mercancías tanto por cuenta propia como a consignación de otros comerciantes ${ }^{17}$. Sin embargo, falleció a bordo del galeón «San Salvador» a poco de salir de Cartagena de Indias. Por el inventario de sus bienes, sabemos que llevaba para beneficiar en Indias tafetanes de Pisa, terciopelos de Génova, damascos, vidrios de Francia, medias de Inglaterra, medias de seda de Toledo y espumillas de Nápoles ${ }^{18}$. Los Sopranis siguieron también vinculados al negocio de la grana. En su testamento, Juan de Sopranis Boquín de Bocanegra declaró que aportó a su matrimonio con Constanza Moreno doce mil reales de a ocho en moneda, plata labrada y grana, la cual vendió después resultando más de dos mil pesos de ganancia. Su hijo, Sebastián de Sopranis, hizo también viaje a Nueva España en la flota del general don Ignacio de Barrios, para realizar el cual le entregó su padre quinientos escudos de plata a cuenta de su legítima ${ }^{19}$. De la actividad de Juan de Sopranis Boquín como cargador hay también constancia indirecta por el hecho de que en 1685, al ir a casar a su hija Clara, prometió al futuro marido de esta por escritura de capitulaciones matrimoniales 10.500 ducados como dote, de los cuales 2.500 quedaron aplazados hasta la vuelta de los galeones a cargo del general don Gonzalo Chacón de Narváez ${ }^{20}$. Se documenta también que pasó a las Indias Agustín de Mendoza y Sopranis, a quien su madre, Juana Sopranis, dio cuatrocientos ducados por cuenta de su legítima para que se aviara en su viaje ${ }^{21}$.

Aunque los Sopranis no figuraron entre los grandes tratantes genoveses que llevaron esclavos a las Indias españolas, como fueron los Vivaldo o los Forne, tuvieron también alguna participación en el tráfico negrero. Así, en 1530 Pedro Juan de Riberol y Benito de Basiniana remitieron sesenta esclavos negros y otras mercaderías a Cuba ${ }^{22}$. En 1634, en los despachos de naos que salieron de los puertos de Sevilla, Sanlúcar de Barrameda, Cádiz, Lisboa e Islas Canarias para cargar esclavos en Cabo Verde, Guinea, Santo Tomé, Angola y La Mina, en virtud de licencias reales, y llevarlos a Nueva España y Tierra Firme figuró Juan Bautista de Sopranis,

16. AGI, Contratación, 439B, N. 5.

17. AGI, Contratación, 5444, N. 152.

18. AGI, Contratación, 462B, N. 6.

19. Archivo Histórico Provincial de Cádiz [AHPC], Protocolos Notariales [PN], CA5155, f. 341-345. Testamento de Juan de Sopranis Boquín de Bocanegra, ante Diego León. Cádiz, 29 de octubre de 1695.

20. AHPC, PN, CA0017, f. 50-55. Testamento en virtud de poder de Clara Sopranis Estopiñán Gaitán de Torres, ante Juan de la Serna y Lara. Cádiz, 1 de febrero de 1687.

21. AHPC, PN, CA5308, f. 318-323. Testamento cerrado de Juana Sopranis, ante Francisco José Camacho. Cádiz, 29 de junio de 1697.

22. AGI, Indiferente, 422, L. 14, f. 129r-130r. 
JUAN JOSÉ IGLESIAS RODRÍGUEZ

MERCADERES EN LAS URBES: LOS SOPRANIS, GENOVESES GADITANOS EN ESPAÑA Y EN AMÉRICA

maestre de la urca «El Ciervo Negro» ${ }^{23}$. A principios de la década de los cuarenta del siglo XVII, este personaje seguía operando como maestre en la Carrera de Indias ${ }^{24}$.

La presencia de los Sopranis en el sistema colonial español no se limitó a la navegación y el comercio en la Carrera de Indias. También hubo miembros de esta familia en puestos de la administración del territorio americano y del ejército de Indias (Iglesias, 2019a). En 1644, el capitán Juan Francisco Sopranis fue nombrado contador, juez y oficial real de isla Margarita ${ }^{25}$. La escueta relación de sus méritos demuestra el origen venal de estos cargos: «No consta tenga más servicios que haber dado 2.000 pesos de contado por este oficio por beneficio del Sr. Conde de Castrillo y decreto de 8 de junio de $1644{ }^{26}$. Este Sopranis aprovechó, pues, las ventas de oficios realizadas durante el reinado de Felipe IV para asegurarse un lucrativo empleo en Indias. No tardaría en rentabilizar la inversión. En 1652, obtuvo en nombre de su hijo, Jerónimo de Sopranis y Escorza, la encomienda de Marigüitar, que comprendía el valle del mismo nombre, útil para el cultivo de maíz y yuca, así como el valle de Urabacoyar, la quebrada de Tocurenare, el asiento de Urichuanocutar, las quebradas de Tacurenán y Carocoriparo, el valle de Periquar y las pesquerías del Paranos, con todos los indios que habitaban en dichos lugares ${ }^{27}$. Otros Sopranis obtuvieron también cargos de la administración colonial. Así, Agustín de Sopranis, caballero de Santiago, fue nombrado en 1643 gobernador de Chucuito, en el virreinato del Perú ${ }^{28}$. Por su parte, Roque Sopranis Centeno, hijo de Jácome Sopranis Boquín de Bocanegra y de Luisa Centeno, nacido en Cádiz en 1655, fue gobernador de Yucatán ${ }^{29}$. Defensor de los indios mayas, a quienes redujo las exacciones sobre el maíz, se granjeó importantes enemistades entre los encomenderos, siendo procesado y depuesto ${ }^{30}$. Más tarde consiguió ser rehabilitado como gobernador. Intentó abrir un camino entre Yucatán y Guatemala y reducir a los indios de aquella zona, los cuales mataron a numerosos españoles ${ }^{31}$.

23. AGI, Contratación, 2891, N. 4.

24. AGI, Contratación, 179, N. 1, R. 11. Autos fiscales de 1641 a 1643 contra varios maestres.

25. GI, Santo Domingo, 43, N. 65.

26. AGI, Indiferente, 161, N. 218. Juan Francisco Sopranis tuvo que entregar tres mil ducados de fianza por la plaza de contador de la Margarita. Pidió licencia para pasar a servir su puesto el 27 de junio de 1645. Su mujer, doña Jerónima de Escorza, no pudo acompañarlo, por hallarse gravemente enferma. AGI, Contratación, 5427, N. 2, R. 24.

27. AGI, Santo Domingo, 43, N. 65.

28. AGI, Contratación, 5426, N. 28.

29. AGI, Indiferente, 2077, N. 383.

30. AGI, México, 363, R. 5, N. 77.

31. AGI, Patronato, 237, R. 4. 
JUAN JOSÉ IGLESIAS RODRÍGUEZ

MERCADERES EN LAS URBES: LOS SOPRANIS, GENOVESES GADITANOS EN ESPAÑA Y EN AMÉRICA

\section{LOS SOPRANIS DE CÁDIZ: LA CONSTRUCCIÓN DEL PATRIMONIO FAMILIAR}

Los negocios americanos estuvieron indudablemente detrás de la fortuna de los Sopranis gaditanos. Pero el proceso de construcción del patrimonio familiar contempló también la intervención de otros factores, entre ellos las dotes, la herencia, las inversiones en propiedades y rentas y las vinculaciones de bienes. El testamento y el inventario de bienes de Jácome de Sopranis proporcionan un interesante ejemplo. El primero de estos documentos, otorgado el 11 de mayo de 1610, incluyó una relación detallada de su hacienda y de la que trajo a su poder Juana de Baricio, su mujer, realizada con el fin de evitar pleitos entre sus hijos ${ }^{32}$. Jácome de Sopranis declaró así que llevó al matrimonio por capital unos 15.000 ducados, procedentes de las legítimas y herencias de sus padres, Esteban Cibo de Sopranis y Luisa Gentil, y de los beneficios que había granjeado con ellas. Como dote, su esposa aportó un juro sobre las alcabalas de la ciudad, unas casas en la calle de la Palma y una heredad en la Isla de León, cargada con un tributo de 600 ducados de principal. Jácome redimió este tributo por cuenta de la dote y mejoró la hacienda de la Isla, cuyo plantío de viñedo estaba perdido, invirtiendo 700 ducados de su propio capital en replantarla con majuelos y en reedificar la casa. Al morir su suegra, Teresa de Oribes, heredó su mujer dos casas altas y bajas, una frente al hospital de la Misericordia y otra en la calle llamada de Sopranis, que dio como dote a Anfión Boquín de Baricio, su yerno, al casarse este con su hija, Luisa de Sopranis. Asimismo, Juana de Baricio heredó unas salinas compuestas de 450 tajos en el lugar de Puente Suazo, y dos mil ducados de vellón ${ }^{33}$. Este proceso de acumulación parecía asegurar un horizonte despejado de bonanza material para la familia. Sin embargo, Jácome de Sopranis tuvo que satisfacer posteriormente sobre sus bienes dotales tres mil ducados, más quinientos de costas y salarios que le fueron exigidos por vía judicial por las cantidades que había dejado a deber su suegro, Simón de Baricio, depositario general que fue de Cádiz, para pagar los cuales tuvo que tomar a censo mil ochocientos ducados, que impuso sobre sus bienes, de los que solo pudo redimir quinientos ducados hasta el momento de su muerte.

Jácome de Sopranis hizo mejora, por vía de mayorazgo, de las casas principales de su morada, frente al hospital de la Misericordia, con sus tiendas y almacenes, a su hijo primogénito, Esteban de Sopranis. Asimismo, renunció a favor de su primogénito el oficio de regidor perpetuo de Cádiz que poseía. El resto de sus bienes fueron

32. AHPC, PN, CA5485, f. 701-706.

33. Esta cantidad se cobró de Diego de Roa, regidor de Cádiz, por concierto de restitución de la dote de Diego de Horozco, depositario general de la ciudad, quien casó con Gracia de Baricio, hermana de Juana de Baricio. Al morir aquella sin hijos, le correspondió en herencia a su madre, y por esta vía la heredó a su vez doña Juana. Ibidem. 
objeto de partición entre sus numerosos hijos. Participaron en ella el citado; Gracia de Sopranis, mujer de Gaspar de Acevedo Bonal, sargento mayor de la Armada del Mar Océano; María de Sopranis; Teresa de Sopranis; Catalina Estopiñán de Sopranis; Simón de Sopranis y Agustín de Sopranis, todos ellos por sí y en nombre de su hermano Juan de la Haya Sopranis, ausente en las islas Canarias. Renunciaron en favor de sus hermanos Luisa de Sopranis, mujer del citado Anfión Boquín de Baricio, y Margarita de Sopranis, casada con el capitán Francisco Fantoni, que se contentaron con las propiedades que habían recibido como dote o por cuenta de su legítima materna ${ }^{34}$. En la dote de la primera entraron las casas de la calle Sopranis; en la de la segunda, las casas principales de la calle de la Palma.

Cuerpo valorado de bienes de Jácome Sopranis (1619)

\begin{tabular}{|c|l|r|l|}
\hline N. & \multicolumn{1}{|c|}{ Descripción } & $\begin{array}{r}\text { Valoración } \\
\text { (maravedís) }\end{array}$ & Observaciones \\
\hline 1 & Oficio de regidor perpetuo & 1.025 .508 & \\
\hline 2 & Heredad de la Isla de León & 822.800 & Casa, bodega y arboleda \\
\hline 3 & Un tributo perpetuo sobre casas & 89.760 & \\
\hline 4 & Un tributo redimible sobre casas & 38.710 & \\
\hline 5 & Un tributo redimible sobre casas & 13.804 & \\
\hline 6 & Un tributo redimible sobre casas & 54.910 & \\
\hline 7 & Casas principales (Misericordia) & 337.480 & Muy maltratada \\
\hline 8 & Casas arrabal de Santa María & 233.241 & \\
\hline 9 & Casas arrabal de Santiago & 159.320 & \\
\hline 10 & Casas corral de las Comedias & 294.848 & \\
\hline 11 & Juro sobre las alcabalas de Cádiz & 1.496 .000 & \\
\hline Total del cuerpo de bienes valorado & $4.566 .800 *$ & \\
\hline
\end{tabular}

*La suma real de las partidas es de 4.566 .380 maravedís. La cantidad consignada es la que aparece en el documento de partición.

Fuente: AHPC, PN, CA5497, f. 978-997. Elaboración propia.

34. AHPC, PN, CA5497, f. 978-997. Partición de los bienes de Jácome de Sopranis, ante Alonso de Villarreal. Cádiz, 3 de junio de 1619. 
JUAN JOSÉ IGLESIAS RODRÍGUEZ

MERCADERES EN LAS URBES: LOS SOPRANIS, GENOVESES GADITANOS

EN ESPAÑA Y EN AMÉRICA

Además de los bienes valorados en la partición, quedaron proindiviso entre los herederos las salinas de Puente Suazo, lindantes con otras de Juan de Villavicencio, calificadas como una hacienda de mucho valor cuando había demanda de sal, pero que en el momento de la partición no estaban trabajadas, además de tener la sal poca estimación, por lo que quedaron para dividir su producto cuando se labraran o se vendieran. Estas salinas constaban originalmente de cuatrocientos tajos. Fueron, en primer lugar, de don Juan de la Haya, deán de la catedral de Cádiz, y del alcaide Diego Hernández de Cartagena. Por muerte del primero de ellos, heredó su parte Teresa de Oribes, hermana suya, quien compró después la otra mitad, unificando la propiedad. Estaban gravadas con un tributo de sesenta cahíces de sal a favor de duque de Arcos, según escritura de reconocimiento firmada en 1573. Llegaron a poder de Jácome Sopranis como parte de la herencia de su mujer, Juana Baricio de Haya, hija de la mencionada Teresa de Oribes. Jácome las amplió hasta completar cuatrocientos cincuenta tajos. En 1593 reconoció ante notario el tributo que pagaban estas salinas al duque de Arcos, y en 1605, por convenio firmado con el alcaide y corregidor de la villa de Rota, jurisdicción de la casa de Arcos, se formalizó la permuta de este pago en especie por otro en dinero de 135 reales anuales, a razón de dos reales y un cuartillo por cahiz de sal ${ }^{35}$.

Del cuerpo de bienes se bajaron 47.600 maravedís que importaron las mandas testamentarias, misas pro anima y gastos notariales de la partición. A cada uno de los beneficiarios le tocaron 564.848 maravedís. La parte de Juan de Haya se distribuyó entre sus hermanos, que quedaron obligados a darle la correspondiente cuenta, así como aquel quedó a su vez obligado a dar cuenta a sus hermanos de los bienes y haciendas que fue a cobrar a las islas de Tenerife y Gran Canaria ${ }^{36}$.

Sin contar con el valor de las citadas salinas, la estructura del capital de Jácome de Sopranis era como sigue:

- Juros: $32,7 \%$

- Propiedades urbanas: $22,5 \%$

35. Archivo Histórico de la Nobleza, Osuna, C. 1594, D. 61. Documentos relativos a la ejecución que se hizo contra los bienes de Jácome de Sopranis por los tributos que debía al duque de Arcos.

36. Juan de Haya Sopranis se asentó definitivamente en Canarias, adonde en un principio fue a hacerse cargo de los bienes familiares que habían heredado él y sus hermanos. Fue sargento mayor y capitán más antiguo de las milicias de Tenerife, castellano del castillo de San Cristóbal y alcalde mayor de Garachico. Asimismo, fue maestre de campo del tercio de La Laguna y ascendiente de don Antonio Porlier y Sopranis, primer marqués de Bajamar. Casó en 1615 en La Laguna con doña María Fieschi (Sancho, 1951: 326). Los derechos sobre un hipotético patrimonio canario correspondiente a los Sopranis de Cádiz se mantuvieron en el tiempo. En 1667, Jácome de Quirós Sopranis declaró que tenía pretensión sobre ciertas tierras de las Canarias, litigadas ante la justicia de aquellas islas de mancomún con otros deudos suyos. AHPC, PN, CA0864, f. 204-205. Codicilo de Jácome de Quirós Sopranis, ante José Mateo. Cádiz, 20 de junio de 1667. 
JUAN JOSÉ IGLESIAS RODRÍGUEZ

MERCADERES EN LAS URBES: LOS SOPRANIS, GENOVESES GADITANOS

EN ESPAÑA Y EN AMÉRICA

- Oficio de regidor perpetuo: $22,5 \%$

- Propiedades rústicas: $18 \%$

- Censos: $4,3 \%$

La propiedad de mayor valor entre sus bienes era el juro impuesto sobre las alcabalas de la ciudad de Cádiz, cuyo principal ascendía a cuatro mil ducados, y sus rentas anuales a 58.659 maravedís, a razón de treinta el millar. Dicho juro perteneció por mitad a Bartolomé de Baricio y Simón de Baricio, abuelo y padre respectivamente de la mujer de Jácome de Sopranis. Figuran a continuación las propiedades urbanas, una de las inversiones predilectas de la burguesía mercantil gaditana, compuestas por un conjunto de casas en los arrabales de Santa María, Santiago y San Francisco, por los que se había recrecido la primitiva villa medieval como consecuencia de la expansión mercantil y demográfica de la ciudad a fines de la Edad Media y comienzos de la Moderna. Los Sopranis tuvieron una gran presencia y protagonismo en el arrabal de Santa María, donde estuvieron sus casas principales y dieron nombre a una de las calles más importantes. El valor del oficio de regidor, equivalente al de las propiedades urbanas, da una idea de la importancia política y económica del control del cabildo como máxima expresión del gobierno urbano. El oficio se valoró en 3.200 ducados, del que se descontaron los 405 pagados por la perpetuidad y otros 53 ducados por la preeminencia de fiel ejecutor que también se le incorporó. Las propiedades rústicas se reducían a la hacienda de la Isla de León, donde la mayor parte de las familias de la oligarquía gaditana tuvieron posesiones, dado que Cádiz carecía casi por completo de término agrícola. Finalmente, la existencia de diversos censos impuestos sobre casas (en el Pópulo o los arrabales de Santiago y San Francisco) pone de manifiesto también que una parte del capital, aunque pequeña en este caso, estaba invertida en préstamos a particulares asegurados mediante una garantía hipotecaria.

A la hora de hablar de las inversiones, resulta también muy interesante el examen del testamento de Esteban Sopranis Baricio, hijo primogénito de Jácome de Sopranis, quien, además del oficio de regidor heredado de su padre, declaró como capital en el momento de su segundo matrimonio con Isabel Boquín 5.400 reales de deudas a su favor; 3.112 reales de plata en poder del capitán Juan Bautista Manito; el mobiliario de su casa (que, como hemos visto, estaba vinculada) y, sobre todo, dos mil ducados que tenía invertidos en el asiento de la avería, con los réditos y ganancias que producían ${ }^{37}$. Se constata así cómo los Sopranis -y con ellos previsiblemente

37. Con palabras de Santiago Hierro Anibarro, «La solución a los problemas de la organización de las flotas pasaba por organizar éstas como un negocio a imagen de los asientos y capitulaciones con que la Corona pactaba la explotación contractual de aquellos servicios que, necesarios para la actividad económica, era incapaz de proporcionar por sí misma. Esta 
JUAN JOSÉ IGLESIAS RODRÍGUEZ

MERCADERES EN LAS URBES: LOS SOPRANIS, GENOVESES GADITANOS

EN ESPAÑA Y EN AMÉRICA

otros miembros de la oligarquía gaditana- reinvirtieron capitales procedentes de los negocios mercantiles en rentas seguras aprovechando las dificultades por las que atravesaba la hacienda real, que forzaron reajustes en el sistema de organización y financiación del comercio colonial ${ }^{38}$. El capital de Esteban de Sopranis se vio incrementado por la dote de Isabel Boquín, integrada por un tributo de mil ducados de principal, más la parte de tierras que le tocó en el cortijo de Casarejos, en términos de Jerez de la Frontera, diversos objetos de plata y nueve mil reales que le pertenecían como parte de una deuda cedida a su favor ${ }^{39}$.

Isabel de Sopranis Boquín de Bocanegra nos ofrece a través de su testamento otro ejemplo del proceso de construcción del patrimonio familiar ${ }^{40}$. Hija de Simón de Sopranis y de Clara Boquín de Bocanegra, casó en primeras nupcias, en el año 1645, con el capitán Miguel Díez de Alda. A este matrimonio llevó como dote mil ducados de vellón por cuenta de sus legítimas paterna y materna, en plata labrada y otros bienes. Díez de Alda, por su parte, aportó como capital suyo unos mil pesos en plata labrada y dinero contante. Durante los pocos años que duró el matrimonio, hasta la muerte de Díez de Alda, hubo bienes multiplicados, probablemente procedentes de los beneficios de la participación en los negocios de Indias, que se dividieron más tarde entre la viuda y los hijos del fallecido capitán. A doña Isabel le correspondieron más de tres mil pesos por razón de su dote, arras y gananciales: dos mil en moneda y el resto en joyas. A cada uno de los dos hijos del matrimonio, Simón (que, como hemos visto se empleó posteriormente como cargador en la Carrera de Indias) y Juan, les cupo dos mil pesos por razón de legítima paterna, cantidades que quedaron bajo la administración de su madre debido a su menor edad. Isabel de Sopranis casó en segundas nupcias en 1652 con su primo Jácome Fantoni. A este nuevo matrimonio llevó por dote los bienes que le quedaron por la muerte de su primer marido, más unas casas en la calle Angosta, mil ducados de vellón en plata labrada y tres mil ducados que cobró por sus legítimas, procedentes del mencionado juro sobre las alcabalas reales de la ciudad. Poco después de este segundo matrimonio, heredó de su tía, Argenta Boquín, unas casas valoradas en dos mil ducados de vellón. Por su parte, el capitán Jácome Fantoni llevó por su capital unas casas principales con tres accesorias en la calle Cobos, otras dos casas en la calle del Rosario, una heredad en la Isla de León, la parte que le correspondía en el

motivación supuso el inicio de la andadura de la avería como negocio privado, en el que unos particulares, diferentes de aquellos que traficaban con Indias, los cargadores, aportaban el capital preciso para la organización de las armadas, beneficiándose del cobro de las cantidades pactadas en el asiento con la Corona». El asiento de la avería se organizó así como una empresa mercantil que guarda semejanzas con las compañías de comercio privilegiadas (Hierro, 2005).

38. AHPC, PN, CA4378, f. 85-92. Testamento de Esteban de Sopranis (1628).

39. Ibidem.

40. AHPC, PN, CA5063, f. 406-415. Testamento cerrado de Isabel de Sopranis (1665). 
JUAN JOSÉ IGLESIAS RODRÍGUEZ

MERCADERES EN LAS URBES: LOS SOPRANIS, GENOVESES GADITANOS EN ESPAÑA Y EN AMÉRICA

fideicomiso que fundó en Florencia su tío abuelo Simone Fantoni (Iglesias, 2008) y mil pesos en dinero de contado.

La fortuna económica de los Sopranis fue apreciable, aunque sin duda modesta si se compara con los grandes capitales de la época dorada del monopolio gaditano del comercio americano, el siglo XVIII. Siguiendo un modelo generalizado entre los miembros de su clase, redirigieron los beneficios del comercio colonial hacia inversiones seguras, inmuebles y rentas sobre todo. Orientaron también sus esfuerzos hacia la participación en el gobierno urbano y la construcción de sólidas alianzas familiares, que contribuyeron a asegurar su influencia en el ámbito gaditano, el control oligárquico del poder local y su proyección decidida hacia el mundo colonial, del que Cádiz constituía un referente inexcusable.

\section{LA INSERCIÓN EN LA OLIGARQUÍA URBANA Y LAS ALIANZAS FAMILIARES}

La oligarquía gaditana moderna, en buena parte de origen mercantil, formó un grupo fuertemente endogámico, pero no completamente cerrado, ya que se fue renovando con aportaciones foráneas atraídas por las inmensas expectativas del comercio atlántico. Los Sopranis, al igual que otras familias extranjeras instaladas en la ciudad, lograron insertarse con rapidez y eficacia en el círculo de los regidores de la ciudad. Este hecho venía favorecido por el carácter de Cádiz como urbe mercantil y presidio militar. La patrimonialización del regimiento en manos de un puñado de familias propició también la transmisión de la titularidad de las regidurías entre sus miembros. Los Sopranis fueron regidores perpetuos, fieles ejecutores y sargentos mayores de Cádiz. Ya hemos visto cómo Jácome Sopranis pagó por la perpetuidad del oficio y por la preeminencia de fiel ejecutor. A partir de ahí, y aunque no vinculó el cargo, varios de sus sucesores ocuparon asiento de regidor perpetuo en el cabildo de la ciudad, así como también la sargentía mayor de las milicias urbanas. Al no tener sucesión, Esteban Sopranis dejó la regiduría perpetua de su propiedad como parte de la herencia de su mujer y sus hermanos, pero manifestando preferencia por que la tomara el segundo de ellos, Simón. El hijo de este, Jácome Sopranis Boquín de Bocanegra, ejerció la sargentía mayor de Cádiz. Otro descendiente de ambos, Simón de Sopranis Boquín de Bocanegra Moreno fue, igualmente, regidor y sargento mayor del batallón de milicias de Cádiz ${ }^{41}$.

La red familiar que tejieron los regidores del cabildo gaditano fue muy tupida (Iglesias, 2016). En ella se insertaron los Sopranis a través de calculados y ventajosos matrimonios. Como ya se ha apuntado, Esteban Cibo de Sopranis, el primer Sopranis gaditano, casó con Luisa Gentil de Estopiñán. Esta procedía, por vía paterna, de una

41. AHPC, PN, CA3761, f. 425-426. 
JUAN JOSÉ IGLESIAS RODRÍGUEZ

MERCADERES EN LAS URBES: LOS SOPRANIS, GENOVESES GADITANOS

EN ESPAÑA Y EN AMÉRICA

familia de comerciantes genoveses, como los propios Sopranis, y, por vía materna, de un antiguo linaje presente en Cádiz desde el siglo XIV. Los Estopiñán estuvieron vinculados al servicio de los condes de Niebla y los duques de Medina Sidonia. Uno de ellos, Pedro de Estopiñán y Virués, comandó la expedición que tomó Melilla el año 1497. Los Estopiñán se encontraban, a su vez, emparentados con otras familias de la oligarquía de Cádiz y Jerez de la Frontera: los Doria, los Centurión, los Virués, los mismos Boquín de Bocanegra, los Cabeza de Vaca, los Carrizosa, los Figueroa y los Villavicencio (Sánchez Saus, 1996; Fornell, 2010; Iglesias, 2016).

En la segunda generación, los Sopranis gaditanos emparentaron con los Baricio y los Marrufo. Simón de Baricio, como hemos visto, fue regidor y depositario general de Cádiz. Al parecer, también comerció en la Carrera de Indias ${ }^{42}$. Los Marrufo, procedentes también de Génova, llevaban largo tiempo asentados en la ciudad, de la que eran también regidores perpetuos.

Nuevas alianzas familiares vinieron a sumarse a la red de parentesco de los Sopranis gaditanos de la tercera generación. Esteban Sopranis casó en primeras nupcias con Isabel Aguíñiga de Negrón, perteneciente también a una familia de regidores perpetuos de Cádiz. El padre de esta, Clemente de Aguíniga, lo era ${ }^{43}$, como también lo había sido Diego de Aguíniga (Iglesias, 2016). En segundas nupcias casó con Isabel Boquín, llevando a cabo así uno de los tres enlaces que protagonizaron los Sopranis de esta generación con dicha familia, pues Simón de Sopranis, hermano de Esteban, contrajo matrimonio con Clara Boquín de Bocanegra, y otra hermana de ambos, Luisa de Sopranis, casó con Anfión Boquín de Baricio. Los Boquín, asimismo de origen genovés, participaron activamente en la Carrera de Indias y formaron también parte del cabildo gaditano. En 1578, Felipe Boquín era maestre de una embarcación de la Carrera, la nao «Nuestra Señora de la Consolación» ${ }^{44}$. Por su parte, Anfión (o Anfreón) Boquín fue piloto de la Carrera de Indias y, en 1591 , era maestre de la nao «Manuela» ${ }^{45}$.

42. En 1591, Antonio Navarro del Prado, capitán general de la flota de Nueva España, ordenó en el puerto de San Juan de Ulúa una averiguación sobre la hacienda y mercaderías dejadas por Simón de Baricio, tripulante de la nao «Manuela», quien había fallecido abintestato en Veracruz. Juan Bautista Boquín, vecino de Cádiz, dueño y capitán de una nao de la Carrera, así como sobrino del fallecido, hizo diligencias para averiguar los bienes de su tío, entre los que se halló una partida de 550 pesos de oro, otros 650 pesos en deudas a favor procedentes de préstamos y de la venta de oro y perlas y diversas partidas de mercancías embarcadas por Baricio: dos cajones de cera labrada, seis pipas merchantas de vino, un balón de papel, unos yunques y otros efectos. AGI, Contratación, 237, N. 6, R. 1.

43. AHPC, PN, CA 4378, f. 85-92. Testamento cerrado de Esteban de Sopranis.

44. AGI, Justicia, 819, N. 3. Pleito de don Martín Cortés, marqués del Valle, con Felipe Boquín.

45. AGI, Constratación, 237, N. 6, R. 1. 
JUAN JOSÉ IGLESIAS RODRÍGUEZ

MERCADERES EN LAS URBES: LOS SOPRANIS, GENOVESES GADITANOS EN ESPAÑA Y EN AMÉRICA

En esta prolífica generación de los Sopranis hay que anotar varios enlaces más con familias de la oligarquía gaditana. En primer lugar, se produjo un doble enlace con los Quirós. En primeras nupcias, Gracia de Sopranis contrajo matrimonio con Duarte de Quirós. En segundas nupcias, lo hizo con Gaspar Acevedo Bonal, sargento mayor de la Armada del Mar Océano. Por su parte, Teresa de Sopranis casó con el capitán Jácome de Quirós, regidor de la ciudad ${ }^{46}$. En segundo lugar, se inicia ahora también el vínculo entre los Sopranis y los Fantoni, otra de las más destacadas familias de la élite gaditana de la época. La estrecha relación entre ambas provino del matrimonio entre Margarita Sopranis y Francisco Fantoni, hijo de Santi Fantoni y Leonor Peri. Los Fantoni fueron de aquellos comerciantes de origen florentino que, junto a otras familias procedentes de la Toscana, como los Federighi y los Bucarelli, habían emigrado a Andalucía en la segunda mitad del siglo XVI (Núñez, 1989). Santi Fantoni se instaló en Cádiz, donde participó en los negocios americanos y fundó una compañía junto con Luigi Federighi que intermedió en el comercio entre el Mediterráneo y el Atlántico. De su matrimonio con Leonor Peri, hija del también florentino Andrea Peri y de la canaria Elvira Fonte, nacieron dos hijos: Juan Andrea y Francisco. Este segundo, propietario de un barco en la Carrera de Indias, la nao «San Pedro», con el que viajaba a Nueva España, fue quien protagonizó el primer enlace con los Sopranis, al casar con Margarita Sopranis, a los que seguirían varios más. El hijo de ambos, Jácome Fantoni Sopranis, casó con su prima Isabel, hija de Simón Sopranis y de Clara Boquín. A su vez, Rafael Fantoni, hijo del anterior matrimonio, celebró nupcias con Ana Sopranis Centeno, hija de Jácome Sopranis y Luisa Ordoñez. Por último, un hijo de Juan Andrea Fantoni, Antonio, casó con Felipa Sopranis, también hija de Simón Sopranis y Clara Boquín y, por tanto, hermana de la citada Isabel. Como se ve, los vínculos matrimoniales y de parentesco entre ambas familias fueron estrechos y numerosos (Iglesias, 2008, 165-166).

En la cuarta generación de los Sopranis gaditanos, se produjo el enlace de Jácome Sopranis Boquín de Bocanegra con Luisa Centeno Ordóñez, hija del general don Roque Centeno, un matrimonio ventajoso que se celebró en el año 1660. Por escrituras de capitulación, Jácome ofreció unas arras de dos mil pesos. A cambio, recibió como dote doce mil pesos escudos: seis mil en dinero de contado, cuatro mil en el valor de una merced de hábito y los dos mil restantes en joyas, de que hicieron entrega el almirante general don José Centeno y don Diego de Centeno, caballeros de Santiago y hermanos de la novia ${ }^{47}$. Fruto de este matrimonio fueron

46. AHPC, PN, CA0864, f. 204-205. Codicilo de Jácome de Quirós, ante José Mateo. Cádiz, 20 de junio de 1667.

47. AHPC, PN, CA2386, f. 258-260. Poder para testar de Jácome Sopranis Boquín de Bocanegra, ante Juan de Borja Pain. Cádiz, 27 de abril de 1704. Sin embargo, en el testamento definitivo, otorgado en virtud de poder, consta que, por fallecimiento de Jácome Sopranis y Luisa 
JUAN JOSÉ IGLESIAS RODRÍGUEZ

MERCADERES EN LAS URBES: LOS SOPRANIS, GENOVESES GADITANOS

EN ESPAÑA Y EN AMÉRICA

el mencionado Roque Sopranis Centeno, gobernador de Yucatán, e Isabel Clara Sopranis Centeno, quienes se vincularon, a su vez, con otras dos importantes familias, los Villavicencio y los Colarte, estos de origen flamenco, por sus matrimonios con Lara Félix de Villavicencio y don José Domingo Colarte, caballero de Calatrava, respectivamente. Este último era hijo de Pedro Colarte o Colaert, comerciante de origen flamenco instalado en Cádiz y casado con María Lila y Valdés, de familia igualmente originaria de los Países Bajos (Bustos, 1991). Para M. Bustos, la unión entre José Domingo Colarte e Isabel Clara Sopranis Centeno, que tuvo lugar en 1682, fue una «boda redonda», por cuanto la novia estaba vinculada al patriciado urbano de Cádiz y aportó una dote de cuatro mil pesos escudos, una encomienda valorada en 600 ducados de renta anual sobre el presidio de Cádiz y una merced de hábito de orden militar, que permitiría a José Domingo convertirse en caballero de Calatrava. A cambio, este aportó unas arras de seis mil pesos y contaba ya, en el momento de su matrimonio, con un capital de 41.000 pesos (Bustos, 1991: 200-201). En esta generación tuvo lugar también la vinculación familiar de los Sopranis con los Díez de Alda (Sancho de Sopranis, 1926).

\section{LA CONSTRUCCIÓN DE LA IDENTIDAD FAMILIAR Y EL CAPITAL SIMBÓLICO}

El patriciado mercantil gaditano, además de compactarse como grupo de poder a través de la construcción de un complejo entramado familiar, puso en marcha también estrategias dirigidas a incrementar su prestigio e influencia social. No les bastaba a sus miembros con las riquezas y con la capacidad de control político que habían adquirido: necesitaban también escenificar eficazmente su posición dominante en el teatro cotidiano de la vida de la ciudad. En esto no se apartaron del modelo de comportamiento de las élites urbanas de la Europa de su tiempo y, muy especialmente, de aquellas que formaban parte de su misma matriz cultural, el occidente europeo mediterráneo. Para lograr construir su identidad grupal y perpetuar su poder, utilizaron muy diversos medios, además de los matrimonios endogámicos: las demostraciones de nobleza, la vinculación de bienes, la exhibición de blasones, la ostentación de riquezas, la adopción de devociones distintivas, la disposición de capillas propias y la fundación de capellanías figuran entre ellos. Formas de escenificación que implicaban la demostración visible de su estatus privilegiado, como medio de imponer, abierta o subliminalmente, su superioridad sobre el resto de la abigarrada y dinámica sociedad de la urbe.

Centeno, su mujer, no quedaron bienes algunos. AHPC, PN, CA2398A, f. 328-330. Testamento en virtud de poder de Jácome Sopranis Boquín de Bocanegra. Cádiz, 16 de mayo de 1715. 
Los Sopranis, como miembros eminentes de aquel patriciado, también utilizaron este tipo de mecanismos. Su procedencia familiar les permitía vincularse a la nobleza genovesa. El apellido Cibo figuraba, según Hipólito Sancho, entre los más ilustres de la nobleza ligur, junto a los Adorno, Centurión, Doria, Grimaldi, Nigro, Salvago, Bocanegra, Sauli o Usodimare (Sancho, 1951: 322-323). Los Sopranis estuvieron representados en el Senado de Génova. Así, por ejemplo, Antonio María Sopranis fue designado senador, junto con Cesare Durazzo y Nicolás Doria, en 1657, según informó al Consejo de Estado el secretario de la embajada de Génova, Diego de Laura $^{48}$.

Sin embargo, no aparece en la familia, al menos con la misma intensidad, aquel afán por ingresar en las órdenes militares que fue común en otras familias de la oligarquía gaditana, especialmente durante el siglo XVII, lo que puede explicarse por el hecho de que los Sopranis mantuvieron en el tiempo la actividad mercantil que otros abandonaron a la segunda o tercera generación familiar para emprender el camino de la nobleza. Aunque había medios eficaces para allanar las dificultades que podían surgir en las averiguaciones de los antecedentes familiares que seguían a la solicitud del hábito de una orden, la dedicación al comercio seguía siendo un hándicap. Así, cuando Jerónimo Boquín pasó las pruebas para obtener el hábito de la orden de Santiago, tuvo que asegurarse de que un testigo de crédito declarara que ni él ni sus ascendientes habían sido mercaderes ni cambiadores, sino que habían vivido como nobles de sus haciendas, rigiendo la ciudad y gobernándola con oficios de regidores y honrados caballeros ${ }^{49}$. No quiere decir ello que ningún Sopranis fuera caballero de hábito, pero sí que lo fueron de manera más tardía. Roque Sopranis Centeno, que fue gobernador de Yucatán, ingresó en la orden de Santiago en $1691^{50}$. A la misma perteneció también Agustín Sopranis ${ }^{51}$. Mayor presencia en las órdenes militares tuvieron, sin embargo, los Fantoni Sopranis. José Fantoni y Sopranis fue caballero de Calatrava ${ }^{52}$. Jácome Fantoni Sopranis y Rafael Fantoni y Sopranis lo fueron, por su parte, de Alcántara ${ }^{53}$.

Únicamente un Sopranis, en este caso una Sopranis, ostentó un título nobiliario y lo hizo tan solo por un breve lapso de tiempo de apenas un año. Se trata de doña Clara Sopranis, hija de Juan de Sopranis Boquín y de Constanza Moreno Estopiñán Gaitán de Torres. Clara Sopranis protagonizó una triste historia. Casó con don Juan Martín Presenti de Toñanejos, marqués de Montecorto, regidor preeminente y juez

48. Archivo General de Simancas, Estado, leg. 3609, 27.

49. Archivo Histórico Nacional [AHN], Órdenes Militares [OM], Santiago, exp. 1155.

50. AHN, OM, Santiago, exp. 7835.

51. AHPC, PN, CA5308, f. 318-323. Testamento cerrado de Juana Sopranis, ante Francisco José Camacho. Cádiz, 29 de junio de 1697.

52. AHN, OM, Calatrava, exp. 880.

53. AHN, OM, Alcántara, exp. 500 y 501. 
JUAN JOSÉ IGLESIAS RODRÍGUEZ

MERCADERES EN LAS URBES: LOS SOPRANIS, GENOVESES GADITANOS EN ESPAÑA Y EN AMÉRICA

de contrabandos de Cádiz. Un matrimonio que le aseguraba una alta posición social y que significaba la incorporación de su familia a la nobleza de título. Sin embargo, este matrimonio no duró mucho. La marquesa de Montecorto murió once meses después de su matrimonio, el día de Navidad de 1686, tras dar a luz a un hija a la que se impuso el nombre de Magdalena ${ }^{54}$.

Al igual que sucedió con otros patricios gaditanos, también encontramos a un Sopranis como familiar del Santo Oficio. La pertenencia a la Inquisición era, al mismo tiempo, una garantía de cristiandad vieja, una herramienta de poder y una forma de distinción social. La familiatura del Santo Oficio a la que nos referimos la ocupó Esteban de Sopranis, sargento mayor y regidor de Cádiz.

La fundación de vínculos fue otra de las características comunes a los miembros de las élites urbanas de la Andalucía atlántica moderna. En otro lugar hemos tratado de profundizar en las razones de este hecho: emulación nobiliaria, perpetuación de la memoria del fundador y de la identidad del linaje, medio de diferenciación social, pero también estrategia calculada de inversión y de manejo eficiente del patrimonio (Iglesias, 2019b). En el caso de los Sopranis, también encontramos esta misma propensión a la vinculación de bienes. No se trata de grandes patrimonios, sino más bien de propiedades urbanas con la que se mejoraba de preferencia a los primogénitos, sujetándolos a su vez a ciertas obligaciones. Poco antes de morir, Jácome Sopranis fundó un vínculo por vía de mayorazgo sobre las casas principales de su morada, incluidas sus tiendas y almacenes, a favor de su primogénito, Esteban, y los descendientes de este, mejorándolo por vía del tercio y el remanente del quinto de sus bienes, con la condición de que todos los hijos del fundador tuviesen habitación en dichas casas mientras no tomasen estado ${ }^{55}$. Este vínculo, por falta de descendencia de Esteban Sopranis, pasó posteriormente a su hermano Simón y sus descendientes. Jácome de Quirós, sobrino del fundador, le agregó diversas propiedades ${ }^{56}$.

Isabel de Sopranis Boquín de Bocanegra también vinculó unas casas de su propiedad, situadas «debajo de la villa», que había heredado de su tía, Argenta Boquín, a favor de su hijo José Francisco, prohibiéndole la venta y enajenación de las mismas, al tiempo que manifestó su voluntad de que su marido, Jácome Fantoni, agregara a este vínculo las casas principales de su morada, en la calle de Cobos.

54. AHPC, PN, CA0017, f. 50-55. Testamento en virtud de poder de doña Clara Sopranis Estopiñán Gaitán de Torres, marquesa de Montecorto, ante Juan de la Serna y Lara. Cádiz, 1 de febrero de 1687.

55. AHPC, PN, CA5485, f. 701-706. La escritura de fundación de este vínculo pasó ante Alonso de Villarreal, escribano público de Cádiz, el 23 de abril de 1610.

56. AHPC, PN, CA2386, f. 258-260. El vínculo pasó de Simón de Sopranis a su hijo, Jácome de Sopranis Boquín de Bocanegra, y de este a Isabel de Sopranis Centeno, mujer de José Domingo Colarte. Fue probablemente por esta vía como las casas principales de los Sopranis pasaron en el siglo XVIII a los Lila, emparentados con los Colarte. 
JUAN JOSÉ IGLESIAS RODRÍGUEZ

MERCADERES EN LAS URBES: LOS SOPRANIS, GENOVESES GADITANOS

EN ESPAÑA Y EN AMÉRICA

Como obligación de los titulares de este vínculo, Isabel de Sopranis estableció que debían mandar celebrar una misa cantada cada año en el convento de los mercedarios descalzos el día de la Santa Cruz, con un estipendio de ocho reales ${ }^{57}$. El hermano de Isabel, Rafael de Sopranis Boquín de Bocanegra mandó asimismo vincular las casas principales de su propiedad a favor de los descendientes de su sobrino, Roque Sopranis Centeno, gobernador y capitán general de la provincia de Campeche, estableciendo varias obligaciones sobre las rentas de sus accesorias con destino a la catedral y el convento de Santa María ${ }^{58}$.

Los Sopranis disfrutaron también de vínculos fundados por otros parientes. Así, por ejemplo, Simón de Sopranis Boquín de Bocanegra, sargento mayor de milicias y regidor de Cádiz, heredó el mayorazgo fundado por su abuelo materno, don Sebastián Moreno Estopiñán, caballero de Santiago y veinticuatro que fue de Jerez de la Frontera ${ }^{59}$. Del mismo modo, Simón Díez de Alda Sopranis fue titular de un vínculo instituido por su abuelo paterno, consistente en varias tutelas impuestas sobre diversas propiedades a su favor, cuando aún era menor, y en dos casas, una principal en la plazuela de las Viudas y otra más pequeña en la callejuela que daba al convento de la Merced ${ }^{60}$.

Como era habitual, estos vínculos se establecieron por vía de mayorazgo, prefiriendo entre sus sucesores siempre al varón a la mujer y al hijo mayor al menor. Los fundadores establecían también las líneas de sustitución para el caso en que se fueran agotando las llamadas a sucesión en primer lugar.

La exhibición de escudos nobiliarios en las fachadas de las casas principales de la familia también fue un medio de hacer visible la nobleza de sus moradores. Sobre la portada de la que fue casa de los Sopranis, en la calle del mismo nombre, fue colocado el blasón familiar, descrito por Hipólito Sancho en los siguientes términos: «león de oro coronado de príncipe posado sobre el mar, en azur, con el ave fénix sin divisa» ${ }^{61}$.

Otro medio de distinguirse del resto de la sociedad y de hacer visible la superioridad de la familia fue la disposición de capillas propias con bóveda para enterramiento de sus miembros. Frédérique Morand otorga gran importancia simbólica a la capilla de la nación genovesa en la catedral vieja de Cádiz (Morand, 2013). No

57. AHPC, PN, CA5063, f. 406-415.

58. AHPC, PN, CA1438, f. 101-108.

59. AHPC, PN, CA3761, f. 425-426. El mismo Sebastián Moreno fundó un patronato para señoras parientes pobres del que fue patrono su también nieto Juan de Sopranis Boquín de Bocanegra. AHPC, PN, CA5155, f. 341-345.

60. AHPC, PN, CA0764, f. 309-312.

61. Este mismo escudo se encuentra en los Sopranis de Cádiz, Canarias y Aragón. Según Sancho, sustituyó al que utilizaron los Sopranis de Génova: la cruz de san Jorge en jefe y el barrón escajeado con el pavón y la divisa Beaulté tout passe (Sancho, 1951: 335). 
hemos encontrado relaciones de los Sopranis, con ella, lo cual no quiere decir que no existieran en algún momento. Los primeros miembros gaditanos de la familia no dispusieron aún de capilla propia. Jácome de Sopranis el Viejo dispuso en su testamento que su cuerpo fuera sepultado en la Iglesia Mayor de la ciudad, pero en la capilla del deán Juan de Haya, donde estaba enterrada Juana de Baricio, su mujer, y no habiendo comodidad para ello, debido a ser pequeña la bóveda, pedía a Clemente de Aguíniga, regidor de la ciudad, como patrón de la Capilla de los Negrones, asimismo situada en la Iglesia Mayor, que se le diera entierro en ella, en la sepultura donde también yacían sus padres, abuelos y hermanos ${ }^{62}$. Por su parte, Esteban de Sopranis, hijo del anterior, mandó ser enterrado en el convento de San Francisco, en el entierro propiedad de su suegro, Clemente de Aguíniga Ochandiano, donde también reposaba el cuerpo de su primera mujer. Más tarde, sin embargo, los Sopranis adquirieron capilla propia, con bóveda para enterramiento, en la iglesia de los padres descalzos de Nuestra Señora de la Merced. Esta capilla, denominada del Santo Cristo (o también del Santo Crucifijo y capilla de los Sopranis), estaba situada a la izquierda de la capilla mayor. Fue comprada de mancomún por Luisa de Sopranis, mujer de Anfión Boquín de Baricio, por su hermana Teresa de Sopranis, mujer de Jácome de Quirós, y por el sobrino de ambas, Jácome Sopranis Boquín de Bocanegra. Los tres compradores se obligaron con los frailes mercedarios a financiar por partes iguales la construcción de un retablo para dicha capilla ${ }^{63}$. Al parecer, esta quedó vinculada, pues así se expresa en el testamento de Jácome Sopranis Boquín de Bocanegra («propia de su vínculo y mayorazgo») ${ }^{64}$. En ella fueron enterrados diversos miembros de la familia, entre ellos, además de los citados, Simón, Juan, Luisa e Isabel de Sopranis Boquín de Bocanegra, Juana de Sopranis y Simón Díez de Alda Sopranis.

La exhibición de riquezas también contribuía a engrosar el imaginario y a alimentar el prestigio del linaje. Para una familia de mercaderes y navegantes a Indias, ello implicaba la posesión de esclavos, de joyas, de muebles y piezas exóticas que actuaban como representaciones visibles de su posición y, al mismo tiempo, como objetos culturales que los significaban como intermediarios entre mundos diversos y lejanos. Los comerciantes de las ciudades atlánticas andaluzas construyeron también por medio de tales elementos una identidad diferenciada que impregnó una cultura urbana distintiva.

La importancia de Cádiz como metrópoli esclavista en la Edad Moderna es bien conocida (Morgado, 2013). Los Sopranis aparecen como propietarios de esclavos

62. AHPC, PN, CA5485, f. 701v.

63. AHPC, PN, CA3554, f. 833-839. Testamento cerrado de Luisa de Sopranis, ante José de Colmenare. Cádiz, 5 de marzo de 1663.

64. AHPC, PN, CA2386, f. 258-260. 
JUAN JOSÉ IGLESIAS RODRÍGUEZ

MERCADERES EN LAS URBES: LOS SOPRANIS, GENOVESES GADITANOS

EN ESPAÑA Y EN AMÉRICA

que mantuvieron a su servicio en el ámbito doméstico, con los que entablaron una relación próxima y cuya asistencia acostumbraron a premiar por voluntad testamentaria con la libertad, a veces sujeta a ciertas condiciones. Así, por ejemplo, en 1610 Jácome Sopranis tenía por sus esclavos a Lázara de la Haya, que nació en su casa, y a los tres hijos menores de esta: Gaspar, de siete años de edad; Ana, de tres años, y Diego, de dos años. Mandó que todos ellos se mantuvieran al servicio de sus herederos por tiempo de quince años, transcurridos los cuales quedarían «libres y horros de todo cautiverio y servidumbre (...) por la voluntad que les tengo y haber servido en mi casa y por la voluntad que les tuvo doña Juana de Baricio, mi mujer» ${ }^{65}$. Luisa de Sopranis dejó también libre por su testamento a María de Sosa, su esclava ${ }^{66}$. Clara de Sopranis Estopiñán llevó a su matrimonio con el marqués de Montecorto, como parte de su dote, una esclava berberisca llamada María de la Candelaria, valorada en 2.300 reales $^{67}$. El presbítero Rafael Sopranis Boquín incluyó una generosa cláusula en su testamento por la que liberaba a Mariana, su esclava negra, y a su hijo Manuel, de diez años de edad, nacido en su casa, mandando darle además a aquella cien ducados de vellón de sus bienes. Asimismo, liberó a otra esclava suya negra, Catalina de Alfonseca, con la condición de que había de quedar en la compañía de la susodicha Mariana, y a un esclavo color membrillo cocho, llamado Antonio de Molina, de más de cincuenta años de edad ${ }^{68}$. Por último, en su testamento, otorgado en 1659, Luisa de Sopranis, doncella, declaró que tenía por su esclava a Francisca de Castro, la cual le tocó en la partición de bienes de sus padres y que sería de edad de unos cuarenta años. Luisa justificó la liberación de esta esclava por «haber servido tantos años a los dichos mis padres y a mí», y la condicionó a que Francisca sirviera a su hermana, Felipa de Sopranis, hasta que tomara estado, pidiéndole a esta que la tratara «con voluntad y agasajo» y mandando a la esclava que observara la misma conducta en la asistencia a dicha su hermana ${ }^{69}$.

La posesión de joyas no era solo un medio de ostentación. Representaba también un modo de inversión del capital y un mecanismo de tesaurización que fácilmente se podía reconvertir en dinero líquido, venta mediante, en momentos de dificultad. Aunque no en exclusiva, fueron sobre todo las mujeres las propietarias de joyas. Estas se transmitían de madres a hijas, o de tías a sobrinas, y formaron también parte de sus bienes dotales. La continua relación con América propició que los Sopranis, como otros miembros del patriciado mercantil gaditano, adquiriesen costosas joyas. Isabel de Sopranis Boquín de Bocanegra mandó en su testamento que se diera a la susodicha Felipa, su hermana,

65. AHPC, PN, CA5485, f. 701-706.

66. AHPC, PN, CA3554, f. 833-839.

67. AHPC, PN, CA0017, f. 50-55.

68. AHPC, PN, CA1438, f. 101-108.

69. AHPC, PN, CA4218, f. 224-232. 
JUAN JOSÉ IGLESIAS RODRÍGUEZ

MERCADERES EN LAS URBES: LOS SOPRANIS, GENOVESES GADITANOS

EN ESPAÑA Y EN AMÉRICA

(...) unos pulsedos (sic) de perlas de que yo uso y ocho anillos de diamantes chicos que cada uno tiene cinco piedras, que llaman cintillos, y un aderezo de benturnia (sic) guarnecido de oro y se compone de gargantilla, joya del pecho con su lazo y una mariposa para el pelo, y le ruego me perdone, que yo quisiera hacer mayor manda, y que me encomiende a Dios ${ }^{70}$.

Asimismo, declaró que en el reparto de los bienes de su primer marido, Miguel Díez de Alda, le habían correspondido, entre otras cosas, tres hilos de perlas, que vendió en 950 pesos, y un taller de plata sobredorada valorado en 300 pesos. Por último, legó a Margarita Fantoni Sopranis, hija de su segundo matrimonio, un rosario de ámbar guarnecido de oro, una gargantilla de esmeraldas con veintiuna piedras, una cadena de oro de tres vueltas, el mencionado taller de plata sobredorada, un vaso de cristal con su pie guarnecido de oro y una imagen de plata de Nuestra Señora de Copacabana, entre otros objetos de valor ${ }^{71}$. Por su parte, Luisa de Sopranis declaró tener dos cadenas, un cabestrillo y un Niño Jesús de oro ${ }^{72}$. Como parte de su dote, Clara Sopranis Estopiñán llevó al matrimonio un aderezo de diamantes, compuesto de joya, zarcillos y gargantilla, valorado en mil seiscientos pesos. De sus bienes formaron también parte dos anillos de oro, uno en forma de corazón con quince diamantes y dieciocho rubíes, y otro con quince diamantes y un zafiro ${ }^{73}$. Rafael de Sopranis Boquín mandó hacer inventario tras su muerte de todas las prendas de oro y plata labrada de su propiedad, que legó a su sobrino Miguel Díez de Alda «a quien he criado y tengo particular amor y cariño» ${ }^{74}$.

Y, junto a las joyas, el mobiliario y el menaje de la casa principal, a la altura de la calidad de sus moradores y un catálogo, también, de su proyección mercantil a escala planetaria. Así, la citada Clara Sopranis Estopiñán, marquesa de Montecorto, tenía en su casa gaditana, entre otros objetos,

(...) un bufete todo guarnecido de carey de tres cuartas de largo y dos tercias de ancho con cantoneras de bronce doradas; otro baulito todo cubierto de carey por dentro y fuera con cantoneras, bisagras, aldabones y bolas por pies de plata, de dos tercias de largo; un baulito de teca con cerradura y bisagras de acero doradas de una tercia y dos dedos de largo, y una colgadura de catre de damasquillo de China a flores, ya usado, que son seis cortinas, cielo y rodapiés. Y, juntamente la ropa blanca y de su vestir en un baúl y una caja grande y algunos juguetes de estrado ${ }^{75}$.

70. AHPC, PN, CA5063, f. 406-415.

71. Ibidem.

72. AHPC, PN, CA3554, f. 833-839.

73. AHPC, PN, CA0017, f. 50-55.

74. AHPC, PN, CA1438, f. 101-108.

75. AHPC, PN, CA0017, f. 50-55. 
JUAN JOSÉ IGLESIAS RODRÍGUEZ

MERCADERES EN LAS URBES: LOS SOPRANIS, GENOVESES GADITANOS

EN ESPAÑA Y EN AMÉRICA

Por su parte, Juana de Sopranis declaró en su testamento que un escaparate de madera, una estera de junco fina del estrado, toda la loza de China y una cama de granadillo de Portugal que tenía en su poder pertenecían a su nieta, por haber sido de la madre de esta ${ }^{76}$. Finalmente, Rafael de Sopranis dejó a su sobrino, entre otras cosas, "dos escritorios guarnecidos de ébano con sus pies» ${ }^{77}$.

Poco o nada podemos decir, en cambio, de la cultura libresca de los Sopranis. En tan solo uno de los testamentos e inventarios que hemos manejado aparecen referencias a libros, y en este caso porque su propietario había seguido la carrera eclesiástica. Se trata del citado Rafael de Sopranis, presbítero, quien mandó en su testamento entregar todos los libros que tenía en su casa, con el estante en que estaban, al prior del convento de Santo Domingo ${ }^{78}$. Sin embargo, en las escrituras de última voluntad de la mayoría de los varones de la familia aparecen con frecuencia, aquí y allá, menciones a sus libros de contabilidad. La cultura mercantil se hacía presente a través de estos imprescindibles instrumentos técnicos de control de sus economías privadas y empresas. Así, Jácome Sopranis, al referirse a un tributo a favor de sus hijos que administraba, impuesto por el racionero Martín de Haya sobre unas casas, indicó que "yo he ido cobrando los corridos de este tributo y tengo en mi libro la razón de lo que hasta el día de hoy he cobrado por esa cuenta». Asimismo, declaró que había entregado a Gracia de Sopranis, su hija, viuda del capitán Duarte de Quirós, lo que constaba en su libro, con la finalidad de que se descontara la correspondiente cantidad de sus legítimas feneciendo la cuenta del mismo. Por último, volvía a remitirse a su libro para la aclaración de las cuentas pendientes con las personas que le habían servido y las posibles contradicciones con tributarios y caseros de sus casas, asegurando que los apuntes que contenía «son ciertos y verdaderos, y en ella se hallará la claricia (sic, por claridad) de mi hacienda» ${ }^{79}$. Otros varios ejemplos de menciones a libros de contabilidad entre los miembros de la familia podríamos traer a colación, pero pensamos que con este resulta suficiente.

Del universo devocional de los Sopranis encontramos también numerosos rastros en sus testamentos y expresiones de última voluntad. Ya hemos hecho referencia a la adquisición de una capilla propia en la iglesia del convento de la Merced, consagrada a Cristo Crucificado. Frédérique Morand enfatiza también la vinculación de la nación genovesa gaditana al monasterio femenino de Santa María, donde ingresaron muchas de las hijas de sus miembros (Morand, 2013: 18). En este aspecto, es cierto que Jácome Sopranis impuso un tributo de setecientos ducados de principal, a razón de a veinte mil el millar, sobre sus casas principales a favor del citado monasterio,

76. AHPC, PN, CA5308, f. 318-323.

77. AHPC, PN, CA1438, f. 101-108.

78. Ibidem.

79. AHPC, PN, CA5485, f. 701-706. 
pero también lo es que su hijo y heredero del vínculo que instituyó sobre dichas casas, Esteban Sopranis, hizo protesta de este gravamen, manifestando que consintió en el pago del citado tributo porque «me hizo [mi padre] obligar por fuerza, y yo vine en ello por el respeto que le tuve (...) porque verdaderamente yo no lo hice de voluntad ${ }^{80}$. Isabel Sopranis Boquín de Bocanegra, por su parte, mejoró en su testamento a su hija Margarita, con condición de que

(...) haya de estar sujeta a la voluntad de don Jácome [Fantoni], su padre, en entrar luego que yo fallezca en el convento de Santa María de esta ciudad en compañía de doña Felipa Boquín, mi tía, para que la eduque y enseñe y que allí permanezca hasta que tome estado de casada o religiosa ${ }^{81}$.

Los Sopranis expresaron también sus devociones a través de la pertenencia a cofradías e institutos religiosos. La citada Isabel Sopranis pidió que el día de su entierro acompañara su cuerpo la cofradía de Santo Domingo Soriano, de la que era hermana, e impuso como nombre a su hija el de Margarita Soriana ${ }^{82}$. Juana Sopranis fue hermana de la Venerable Orden Tercera de San Francisco. Agustín Mendoza Sopranis, por su lado, pidió en su testamento que su cuerpo fuera sepultado en el convento de los frailes franciscanos descalzos de la villa de Puerto Real, del que era síndico ${ }^{83}$.

Las disposiciones sobre el propio funeral, misas pro anima y mandas piadosas testamentarias se sitúan en un ambiguo terreno entre el miedo a la muerte y el Más Allá, la piedad personal y la representación social. Jácome Sopranis dispuso que a su funeral, acompañado de música, asistiesen todos los capellanes y cofradías de la ciudad, así como los frailes de San Francisco, «haciéndose lo demás que se suele hacer con hombres de mi calidad». Su hijo, Esteban de Sopranis, familiar del Santo Oficio, regidor y sargento mayor de Cádiz, ordenó que se dijeran hasta dos mil misas por su alma y las almas de sus padres y su primera mujer. Ese número ascendió a tres mil misas en el caso de Isabel de Sopranis Boquín de Bocanegra, quien, además, dispuso que el día de su entierro se hiciera oficio de honras enteras y la acompañasen con la cruz alta los clérigos y capellanes de la Santa Iglesia Catedral, así como los religiosos de los conventos de San Francisco, Santo Domingo, San Agustín y San Juan de Dios, llevando su cuerpo en hombros estos últimos. La exageración barroca llega al paroxismo en el codicilo que otorgó Simón Díez de Alda Sopranis a bordo del galeón «San Salvador», por el que dispuso que se dijeran por su alma catorce mil misas rezadas, además de que se repartieran seiscientos pesos entre pobres

80. AHPC, PN, CA4378, f. 85-92.

81. AHPC, PN, CA5063, f. 406-415.

82. Ibidem.

83. AHPC, PR81, f. 173-182. 
JUAN JOSÉ IGLESIAS RODRÍGUEZ

MERCADERES EN LAS URBES: LOS SOPRANIS, GENOVESES GADITANOS

EN ESPAÑA Y EN AMÉRICA

vergozantes y conventos de religiosos y religiosas pobres y otras diversas mandas, nada despreciables, a favor de San Antonio de Padua, la Virgen del Rosario, San Nicolás de Bari y la cofradía de Benditas Ánimas del Purgatorio de Cádiz ${ }^{84}$. Por el contrario, Juana Sopranis encargó a sus albaceas que su entierro fuese «con toda modestia y sin profanidad». La humildad como otra forma en apariencia diametralmente opuesta, pero en el fondo sustancialmente idéntica, de la ostentación barroca.

La fundación de capellanías representó otra forma de manifestación piadosa, al tiempo que un mecanismo para la perpetuación de la memoria de los fundadores y para contribuir a la congrua de los descendientes clérigos. De alguna manera, mutatis mutandis, podría considerarse un equivalente en el plano espiritual de los mayorazgos laicos. Esteban de Sopranis fundó una capellanía y memoria de misas en el convento de San Francisco, a la que dotó con los 2.500 ducados que heredó de Isabel de Aguíniga, su primera mujer, «mostrando en esta parte el amor que la tuve y procurando convertirlos en bien de su alma y mía, hallándome agradecido a la voluntad que me tuvo». Rafael de Sopranis Boquín fundó hasta tres capellanías perpetuas colativas, cada una de ellas dotada con veinte mil reales de vellón, que habrían de imponerse sobre fincas seguras y saneadas que redituaran un cinco por ciento anual, cuyo producto habría de invertirse en misas. La primera de estas capellanías la fundó por su alma y las de los difuntos de su obligación. La segunda, por las almas de aquellas personas por las que tuviese algún cargo, para que les sirviera de sufragio, y, no habiendo ninguna, por las almas del Purgatorio. La tercera, más exótica, pero también más expresiva del universo material y mental de aquel Cádiz americano y colonial, la fundó

(...) para que perpetuamente sea sufragio del alma del indio más necesitado que en todo tiempo estuviese en el Purgatorio, para que salga a gozar de la gloria, y después de ella por el alma o almas de dichos indios a que su divina Majestad fuere servido aplicarlas para que más brevemente consigan su descanso ${ }^{85}$.

\section{CONCLUSIONES}

El estudio de caso y el análisis denso, reduciendo el campo de observación a una sola familia, nos ha permitido efectuar en este trabajo un acercamiento a la realidad material y mental del patriciado mercantil gaditano de los siglos XVI y XVII. El interés de este estudio radica, principalmente, en el papel jugado por Cádiz en el entramado de relaciones mercantiles de la época, debido a su privilegiada situación

84. AGI, Contratación, 462B, N. 6.

85. AHPC, PN, CA1438, f. 101-108. Testamento de don Rafael Sopranis y Boquín, presbítero. Cádiz, 18 de junio de 1699. 
entre el Mediterráneo y el Atlántico, entre la Europa meridional, la Europa del norte, África, los archipiélagos atlánticos y el continente americano. Cádiz fue una base importante en las rutas del comercio internacional y un nexo eficaz entre mundos diversos. De ahí la importante presencia de colonias mercantiles extranjeras en esta ciudad, que iba camino de convertirse en el emporio del orbe que evocó fray Jerónimo de la Concepción.

Los Sopranis formaron parte de esa abigarrada realidad cosmopolita del Cádiz de los primeros siglos modernos, como integrantes de una de las principales naciones que participaron en la actividad mercantil de la ciudad, la genovesa. Llegados a Cádiz a mediados del siglo XVI, tuvieron una importante presencia en la Carrera de Indias y en las colonias americanas, al tiempo que mantuvieron una estrecha relación familiar y comercial con las islas Canarias. Se incorporaron con facilidad relativa a la oligarquía gaditana, obteniendo asientos de regidor en el cabildo de la ciudad y puestos de relevancia en la milicia urbana. Tejieron una densa madeja de vínculos familiares, mediante numerosos y sucesivos enlaces matrimoniales, con la mayor parte de los linajes que detentaban el gobierno de la ciudad, tanto de origen autóctono como foráneo. La construcción de la fortuna material y del capital simbólico del linaje tuvo mucho que ver con esa capacidad de entablar y manejar unas relaciones que hicieron del patriciado gaditano un grupo compacto y de perfiles bien definidos.

La aproximación a la historia de los Sopranis que hemos realizado en este trabajo no se limita, sin embargo, a su actividad económica ni a su comportamiento social. Los mercaderes desempeñaron un importante papel en las urbes como productores y consumidores de objetos y manifestaciones culturales. Contribuyeron, por tanto, de manera intensa a la conformación de una cultura urbana de contornos bien definidos. Ello es especialmente significativo en las ciudades mercantiles, abiertas a los contactos y relaciones con otros ámbitos geográficos, auténticos crisoles en los que se fundieron individuos, costumbres y tradiciones de muy diverso origen. Cádiz y sus mercaderes resultan, al respecto, un observatorio privilegiado, como conector destacado de relaciones intensas y profusas, la ciudad, y como mediadores culturales navegando entre mundos de orillas múltiples, los hombres. Así, en el rastro dejado por los Sopranis encontramos las evidencias casi omnipresentes de una realidad interconectada y heterogénea (los barcos, las mercancías, las navegaciones, los tratos, la plata, los ecos de las colonias, los esclavos, las joyas, los productos exóticos...), al tiempo que las de un universo mental que modeló y condicionó la particular cosmovisión del activo segmento social del que formaron parte. Agentes de la construcción de un mundo nuevo, el venero que han proporcionado para penetrar en la realidad que les fue propia, la de los mercaderes en las urbes, puede juzgarse, pues, fértil y provechoso. 


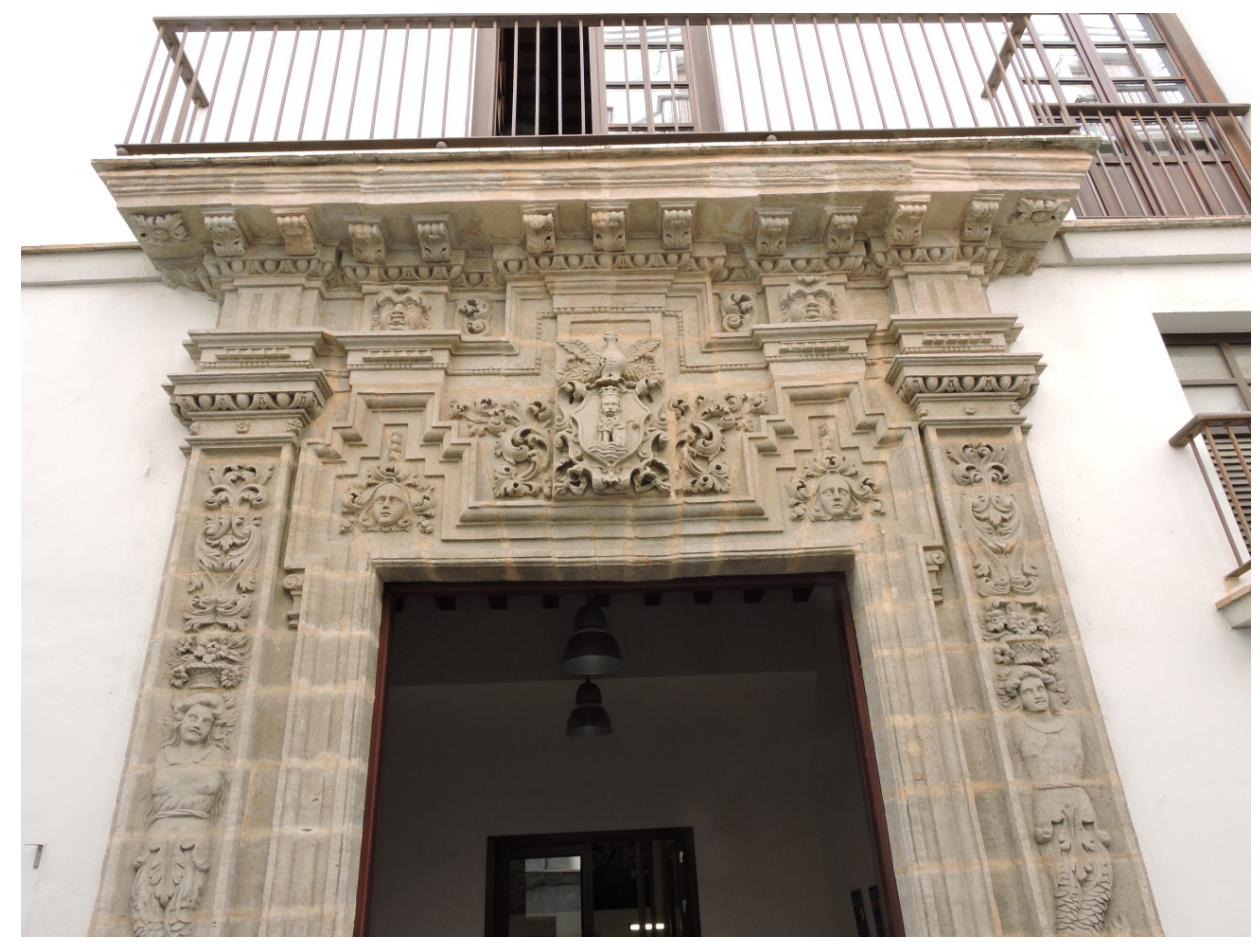

Casa de los Lila, con el escudo de los Sopranis en la portada (fotografía del autor).

\section{BIBLIOGRAFÍA}

Bello León, J. M. (1993). Mercaderes extranjeros en Sevilla en tiempos de los Reyes Católicos. Historia. Instituciones. Documentos, 20, 47-84.

Boscolo A. (1974). Genova e Spagna nei secoli XIV e XV: una nota sugli insediamenti. En Atti del I Convegno Internazionale di Studi Colombiani (pp. 37-49) Genova.

Bustos Rodríguez, M. (1991). Burguesía de negocios y capitalismo en Cádiz: los Colarte (1650-1750). Cádiz: Diputación Provincial.

Bustos Rodríguez, M. (2005). Cádiz en el sistema atlántico. La ciudad, sus comerciantes y la actividad mercantil (1650-1830). Madrid: Sílex.

Concepción, J. de (1690). Emporio del Orbe. Cádiz ilustrada. Ámsterdam.

Crespo Solana, A. (2015). El más amplio Atlántico: redes mercantiles, comunidades globales, en J. J. Iglesias Rodríguez, R. M. Pérez García y M. F. Fernández Chaves (eds.). Comercio y cultura en la Edad Moderna (pp. 47-68). Sevilla: Editorial Universidad de Sevilla. 
JUAN JOSÉ IGLESIAS RODRÍGUEZ

MERCADERES EN LAS URBES: LOS SOPRANIS, GENOVESES GADITANOS

EN ESPAÑA Y EN AMÉRICA

D’Arienzo, L. (1986). Mercanti italiani fra Siviglia e Lisbona nel Quattrocento. En La presenza italiana nel basso Medioevo, Atti del II Colloquio Italiano-Spagnolo (pp. 35-50). Bologna: Cappelli.

D’Arienzo, L. (1993). Le colonie genovesi di Siviglia, Cadice, Jerez e Puerto de Santa Maria alla vigilia del viaggio di scoperta colombiano attraverso una fonte fiscale sulla guerra di Granada (l'asedio di Baza del 1489). En Sardegna, Mediterraneo e Atlantico tra Medioevo e età Moderna (pp. 133-183). Cagliari: Bulzoni.

De la Rosa Olivera, L. (1972). Francisco de Riberol y la colonia genovesa en Canarias. Anuario de Estudios Atlánticos, 18, 61-198.

Fornell Fernández, F. J. (2010). Linajes gaditanos en la Baja Edad Media. Cádiz: Universidad de Cádiz.

González Arce J. D. (2010). El consulado genovés de Sevilla (siglos XIII-XV). Aspectos jurisdiccionales, comerciales y fiscales. Studia Historica. Historia Medieval, 28, 179-206.

González Arévalo, R. (2020). Del Adriático al Atlántico: Venecia y Cádiz entre navegación, diplomacia y comercio (siglos XIV-XV). Hispania, 264, 11-45.

Gruzinski, S. (2010). Las cuatro partes del mundo. Historia de una mundialización. México: Fondo de Cultura Económica.

Heers, J. (1982). Los genoveses en la sociedad andaluza del siglo XV: orígenes, grupos, solidaridades. En Hacienda y comercio. Actas del II Coloquio de Historia Medieval Andaluza (pp. 419-444). Sevilla: Diputación Provincial.

Herrero Sánchez, M. y Kaps, K. (2017). Merchants and Trade Networks in the Atlantic and the Mediterranean, 1550-1800. Connectors of commercial maritime Systems. New York: Routledge.

Hierro Aníbarro, S. (2005). El asiento de avería y el origen de la compañía privilegiada en España. Revista de Historia Económica, 23(Extra 1), 181-212.

Hopkins, A. (coord.). (2002). Globalization in World History. Nueva York: Norton.

Horozco, A. de (1845). Historia de la ciudad de Cádiz. Cádiz: Imprenta de Don Manuel Bosch.

Iglesias Rodríguez, J. J. (2008). El árbol de sinople. Familia y patrimonio entre Andalucía y Toscana en la Edad Moderna. Sevilla: Universidad de Sevilla.

Iglesias Rodríguez, J. J. (2016). Redes familiares y élites mercantiles internacionales en la Andalucía atlántica moderna (Cádiz, siglos XVI y XVII). En F. Sánchez-Montes, J. J. Lozano y A. Jiménez Estrella. Familias, élites y redes de poder cosmopolitas de la Monarquía Hispánica en la Edad Moderna (pp. 143-160). Granada: Comares.

Iglesias Rodríguez, J. J. (2019a). La proyección atlántica de las élites mercantiles gaditanas a comienzos de la Edad Moderna. En M. F. Fernández Chaves, R. M. Pérez García y B. Perez. Mercaderes y redes mercantiles en la Península Ibérica, siglos XV-XVIII (pp. 223-243). Lisboa-Sevilla-París: Editorial Universidad de Sevilla-Cátedra Alberto Benveniste-Éditions Hispaniques.

Iglesias Rodríguez, J. J. (2019b). Los procesos de acumulación y vinculación patrimonial de la propiedad en las nuevas élites atlánticas de la Andalucía moderna. e-Spania. Revue électronique d'études hispaniques, 34 (en línea). 


\section{JUAN JOSÉ IGLESIAS RODRÍGUEZ \\ MERCADERES EN LAS URBES: LOS SOPRANIS, GENOVESES GADITANOS EN ESPAÑA Y EN AMÉRICA}

Iglesias Rodríguez, J. J. (2020). Mercaderes italianos en las ciudades atlánticas del Sur de España a comienzos de la Edad Moderna. En Storia dei Mediterranei. Città, porti e scambi tra l'età antica e la modernità (pp. 141-181). Modica: Edizioni di Storia e Studi Sociali.

Igual Luis, D. y Navarro Espinach, G. (1997). Los genoveses en España en el tránsito del siglo XV al XVI. Historia. Instituciones. Documentos, 24, 261-332.

Ladero Quesada, M. Á. (1989). Los genoveses en Sevilla y su región (s. XIII-XVI): elementos de permanencia y arraigo. En Los mudéjares de Castilla y otros estudios de historia medieval andaluza. Granada: Universidad de Granada.

Marrero, M. (1950). Los genoveses en la colonización de Tenerife, 1496-1501. Revista de Historia, 89, 52-65.

Martín Gutiérrez, E. (2006). Nuevos datos sobre la población y los genoveses en la ciudad de Cádiz. Una relectura del padrón de vecinos de 1467. En la España medieval, 29, 187-223.

Melis, F. (1990). I mercanti italiani nell'Europe medievale e rinascimentale, Florencia: Le Monnier.

Morand, F. (2013). La nación nómada: los genoveses en Cádiz desde finales del XV hasta mediados del siglo XVII. En J. I. Ruiz Rodríguez y I. Sosa Mayor (dir.), Construyendo identidades: del protonacionalismo a la nación (pp. 234-273), Alcalá de Henares: Universidad de Alcalá.

Morgado García, A. (2013). Una metrópoli esclavista: el Cádiz de la modernidad. Granada: Editorial Universidad de Granada.

Núñez Roldán, F. (1989). Tres familias florentinas en Sevilla: Federighi, Fantoni y Bucarelli. En Presencia italiana en Andalucía, siglos XIV-XVII. Actas del II Coloquio HispanoItaliano. Sevilla: Escuela de Estudios Hispano-Americanos, 23-50.

Otte, E. (1996). Sevilla y sus mercaderes a fines de la Edad Media. Sevilla: Universidad de Sevilla.

Perez, B. (2016a). Les marchands de Séville. Une société inquiète (XVe-XVIe siècles). París.

Perez, B. (2016b). Francisco de Riberol. Un genovés sevillano canario en el sistema europeo de relaciones. En J. J. Iglesias y J. J. García Bernal (eds.), Andalucía en el mundo atlántico moderno. Agentes y escenarios (pp. 195-213). Madrid: Sílex.

Perez, B. (2018). Juegos y desafíos de las redes mercantiles. Conversos, burgaleses y genoveses en la Sevilla de los primeros tiempos americanos. En J. J. Iglesias, J. J. García Bernal y J. M. Díaz Blanco (eds.), Andalucía en el mundo atlántico moderno. Ciudades $y$ redes (pp. 303-341). Madrid: Sílex.

Pellegrini, A. (2003-2004). Los genoveses en España. La colonia de Cádiz. Boletín de la Real Sociedad Geográfica, 139-140, 137-174.

Pike, R. (1966). Entreprise and Adventure. The Genoese in Seville at de Opening of the New World. New York: Cornell University Press.

Pistarino, G. (1985). Presenze ed influenze italiane nel Sud della Spagna (Secc. XII-XV). En B. Torres Ramírez y J. J. Hernández Palomo (dirs.), Presencia italiana en Andalucía, 
JUAN JOSÉ IGLESIAS RODRÍGUEZ

MERCADERES EN LAS URBES: LOS SOPRANIS, GENOVESES GADITANOS

EN ESPAÑA Y EN AMÉRICA

siglos XIV-XVII. Actas de I Coloquio Hispano-Italiano (pp. 21-51). Sevilla: Escuela de Estudios Hispano-Americanos.

Ríos Toledano, D. (2018). Cádiz y el comercio marítimo genovés en el siglo XIV. Medievalismo, 28, 271-293.

Rumeu de Armas, A. (1956-1957). España en el África Atlántica, 2 vols. Madrid: Consejo Superior de Investigaciones Científicas.

Rumeu de Armas, A. (1976). Cádiz, metrópoli del comercio con África en los siglos XV y XVI. Cádiz: Caja de Ahorros de Cádiz.

Sánchez Herrero, J. (1981). Cádiz, la ciudad medieval y cristiana (1260-1525). Córdoba: Confederación Española de Cajas de Ahorros.

Sánchez Saus, R. (1996). Linajes medievales de Jerez de la Frontera. Sevilla: Guadalquivir.

Sánchez Saus, R. (2005). Cádiz en la época medieval. En VV. AA., Historia de Cádiz (pp. 147-281). Madrid: Sílex.

Sancho de Sopranis, H. (1926). La vinculación Díez de Alda-Sopranis (1681-1870). Noticias bistórico-genealógicas. Cádiz: Editorial Rodríguez de Silva.

Sancho de Sopranis, H. (1939). Los genoveses en Cádiz antes de 1600, Jerez de la Frontera: Ayuntamiento de Jerez de la Frontera-Sociedad de Estudios Históricos Jerezanos.

Sancho de Sopranis, H. (1948). Los genoveses en la región gaditano-xericense de 1460 a 1800. Hispania, 32, 353-402.

Sancho de Sopranis, H. (1950). Los Sopranis en Canarias, 149?-1620. Revista de Historia, 95-96, 318-336. 
